\title{
Helminth parasites of Artemia franciscana (Crustacea: Branchiopoda) in the Great Salt Lake, Utah: first data from the native range of this invader of European wetlands
}

\author{
Stella Redón ${ }^{1}$, Nicole J. Berthelemy ${ }^{2}$, Yasen Mutafchiev ${ }^{3}$, Francisco Amat ${ }^{1}$, Boyko B. Georgiev ${ }^{3}$ and \\ Gergana P. Vasileva ${ }^{3}$ \\ ${ }^{1}$ Institute of Aquaculture Torre de la Sal, CSIC, Castellón, Spain; \\ ${ }^{2}$ Department of Zoology, College of Science, Weber State University, Ogden, USA; \\ ${ }^{3}$ Institute of Biodiversity and Ecosystem Research, Bulgarian Academy of Sciences, Sofia, Bulgaria
}

\begin{abstract}
The present study is the first survey on the role of Artemia franciscana Kellogg as intermediate host of helminth parasites in its native geographical range in North America (previous studies have recorded nine cestode and one nematode species from this host in its invasive habitats in the Western Mediterranean). Samples of Artemia franciscana were collected from four sites in the Great Salt Lake (GSL), Utah, across several months (June-September 2009). A. franciscana serves as intermediate host of five helminth species in this lake. Four of them are cestodes: three hymenolepidids, i.e. Confluaria podicipina (Szymanski, 1905) (adults parasitic in grebes), Hymenolepis (sensu lato) californicus Young, 1950 (adults parasitic in gulls), Wardium sp. (definitive host unknown, probably charadriiform birds), and one dilepidid, Fuhrmannolepis averini Spassky et Yurpalova, 1967 (adults parasitic in phalaropes). In addition, an unidentified nematode of the family Acuariidae was recorded. Confluaria podicipina is the most prevalent and abundant parasite at all sampling sites, followed by $H$. (s. l.) californicus. The species composition of the parasites and the spatial variations in their prevalence and abundance reflect the abundance and distribution of aquatic birds serving as their definitive hosts. The temporal dynamics of the overall helminth infections exhibits the highest prevalence in the last month of study at each site (August or September). This native population of $A$. franciscana from GSL is characterised with higher prevalence, intensity and abundance of the overall cestode infection compared to the introduced populations of this species in the Palaearctic Region. The values of the infection descriptors in the native population of $A$. franciscana are slightly lower or in some cases similar to those of the Palaearctic species Artemia parthenogenetica Barigozzi (diploid populations) and Artemia salina (Linnaeus) in their native habitats.
\end{abstract}

Keywords: American brine shrimp, helminth larvae, Cestoda, cysticercoids, Nematoda

This article contains supporting information (Fig. S1, Tables S1-S3) online at http://folia.paru.cas.cz/suppl/2015-62-030.pdf

Brine shrimps of the genus Artemia Leach (Crustacea: Branchiopoda: Anostraca) are plankters in hypersaline habitats throughout the world, often dominating their food webs (Amat et al. 1995, Wurtsbaugh and Gliwicz 2001). They are an essential food resource for aquatic birds (Caudell and Conover 2006, Sánchez et al. 2006, Varó et al. 2011). The genus Artemia includes six bisexual species and a group of parthenogenetic populations with diverse ploidy ( $2 \mathrm{n}$ and $4 \mathrm{n}$ ) known as Artemia parthenogenetica Barigozzi (see Abatzopoulos et al. 2002). Only two bisexual species occur in the New World: Artemia franciscana Kellogg and Artemia persimilis Piccinelli et Prosdocimi. The former is widespread in the Americas (Triantaphyllidis et al. 1998, Abatzopoulos et al. 2002) while the geo- graphical range of the latter is restricted to southern South America (Triantaphyllidis et al. 1998).

The American brine shrimp A. franciscana serves as an essential food source for millions of birds at the Great Salt Lake, Mono Lake and other hypersaline wetlands in North America. In addition, these shrimps support a multi-million dollar commercial harvest (Great Salt Lake Ecosystem Program 2010). Since the 1980s, their use in aquaculture and pet industries has resulted in their introductions into ecosystems outside of their native range. In addition, migratory birds play an important role as efficient dispersal vectors of Artemia cysts (Green et al. 2005, Sánchez et al. 2007a, 2012a). Consequently, A. franciscana has invaded many hypersaline wetlands in southern Europe (for

Address for correspondence: S. Redón, Institute of Aquaculture Torre de la Sal, CSIC, Ribera de Cabanes s/n, 12595 Castellón, Spain. Phone: +34 9643195 00; Fax: +349643195 09; E-mail: stellarc.bio@gmail.com 
review, see Amat et al. 2005). In the western Mediterranean, $A$. franciscana has been recorded in Portugal, Spain, France, Italy, Tunisia and Morocco (Hontoria et al. 1987, 2012, Thiéry and Robert 1992, Amat et al. 2005, 2007, Mura et al. 2006, Ben Naceur et al. 2010, Pinto et al. 2013, Scalone and Rabet 2013) and it has become a threat for the native biodiversity.

Currently, there is a growing interest in the role of parasites in biological invasions (Torchin et al. 2003, Prenter et al. 2004, Dunn 2009, Dunn et al. 2012). Native species of Artemia from western Mediterranean salterns are known to be intermediate hosts of 12 cestode species parasitising flamingos, grebes, waders, shelducks and gulls (reviewed by Georgiev et al. 2005, Vasileva et al. 2009). Cestode infections are associated with physiological, reproductive and behavioural alterations with a negative impact on native brine shrimps (e.g. Amat et al. 1991, Sánchez et al. 2006, 2007b, 2009a). Nine of those avian cestodes as well as one nematode species were recorded in introduced populations of $A$. franciscana in the western Mediterranean (Georgiev et al. 2007, 2014, Vasileva et al. 2009, Sánchez et al. 2012b). Previous studies have shown lower infection rates in this invasive brine shrimp than in native $A$. parthenogenetica (diploid populations) and A. salina (Linnaeus), which, associated with the negative impact of parasites on native hosts, could partly explain the competitive success and the rapid invasion of $A$. franciscana in the Iberian Peninsula (Georgiev et al. 2007, 2014). However, the lack of information about helminth infections in A. franciscana populations in its native range does not allow better understanding of the role of parasites in the invasion process of this brine shrimp in Europe.

The aim of the present study is to perform a systematic survey on larval helminth parasites in A. franciscana in its native habitat (Great Salt Lake, USA) and to reveal spatial and temporal variations in the parasitic infections. We also compare the species composition of helminth parasites and their infection parameters in the native and introduced populations of $A$. franciscana in order to better understand the differences of its role as intermediate host in native and invaded habitats.

\section{MATERIALS AND METHODS}

\section{Sampling localities and dates}

Brine shrimps were collected from four sites around the Great Salt Lake (GSL), Utah, USA (Fig. S1) during June-September 2009. These sites were selected on the basis of their accessibility and previous data on concentrations of birds (Paul and Manning 2002; S.R. and N.J.B. - unpubl. data). They were near the Antelope Island causeway (AIC, depth $0.1-0.2 \mathrm{~m}$ ), open water north of Antelope Island (AI, depth 2.0-2.5 m), Ogden Bay (OB, depth $0.2-0.7 \mathrm{~m}$ ) and Saltair Marina (SM, depth $>3 \mathrm{~m})$. The salinity was $105-150 \mathrm{~g} / 1$ (measured on sampling days), except for AIC in June (20 g/l ) where no brine shrimps were present and in August (47 g/l ). Water temperature (measured on sampling days) varied $20-28^{\circ} \mathrm{C}$. One sample per month and site was collected from surface waters $(0-0.5 \mathrm{~m})$.

\section{Processing brine shrimp samples and helminth identification}

Individuals of Artemia franciscana were collected with a planktonic hand net $(500 \mu \mathrm{m}$ mesh size $)$. They were transferred into plastic containers (5 1) filled with lake brine and transported to the College of Sciences, Weber State University (Ogden). Samples were arranged into several containers (4 1) and phytoplankton mass culture (Tetraselmis sp.) was added to keep Artemia specimens alive for few days until they were studied. Random samples were collected and fixed in $70 \%$ ethanol for future parasite survey and identification.

Parasites were identified and counted by examining adult $\mathrm{Ar}$ temia specimens in temporary glycerol mounts (at least $24 \mathrm{~h}$ after being mounted) under a compound microscope. If the identification of the cysticercoids was not possible at this stage, whole brine shrimps or isolated cysticercoids were mounted in Berlese's medium to facilitate observations of the rostellar hooks. Larval nematodes were detected, counted and characterised in temporary glycerol whole mounts.

Cysticercoids were identified by comparisons with previous descriptions (Maksimova 1977, 1981, Georgiev et al. 2005, Vasileva et al. 2009). The terminology of cysticercoids follows Chervy (2002). The identification of the cysticercoids of Hymenolepis (sensu lato) californicus Young, 1950 needed re-examination of paratypes from the U.S. National Parasitological Collection (USNPC No. 46488).

The metrical data in the descriptions are based on specimens mounted in glycerol unless otherwise stated and are given as the range, with the mean and the number of measurements taken in parentheses. The measurements are in micrometres except where otherwise stated.

\section{Bird data}

Information about the presence of birds was obtained from a GSL Waterbird Survey carried out from April 2008 to September 2011 (Table S1). The monthly census of aquatic birds was performed in the frame of the GSL Ecosystem Program (Utah Division of Wildlife Resources). Additional data, based on the Five-Year Report of the GSL Waterbird Survey (1997-2001), were also used (Paul and Manning 2002).

\section{Parameters of infection and statistical analysis}

Infection descriptors prevalence (P\%), mean intensity (MI) and mean abundance (MA) were used as defined by Bush et al. (1997). These parameters were calculated for the total helminth infection and for each helminth species in adult individuals of A. franciscana per sampling site and month. In addition, the relative abundance (RA\%) of each cestode species was determined for each locality.

Non-parametric statistics were utilised due to the lack of normality in the distributions of the infection parameters after several transformations. Statistical analyses were carried out using SPSS 15.0 for Windows package (SPSS Inc., Chicago, IL, USA). The significance of the variations in prevalence was evaluated using Chi-square test $\left(\chi^{2}\right)$ or Fisher's exact test for small sample size. Kruskal-Wallis and Mann-Whitney $U$ tests were used to analyse the differences in mean intensity and mean abundance. Significance was assumed at $P \leq 0.05$. $P$ values were always Bonferronicorrected to avoid type I errors (Miller 1981). 
Table 1. Prevalence $(\mathrm{P} \%)$, intensity, mean intensity $(\mathrm{MI} \pm \mathrm{SE})$ and mean abundance $(\mathrm{MA} \pm \mathrm{SE})$ of helminth parasites in adult brine shrimps (Artemia franciscana Kellogg) from the Great Salt Lake.

\begin{tabular}{|c|c|c|c|c|c|}
\hline \multirow{2}{*}{ Helminth infection } & \multirow{2}{*}{$\begin{array}{c}\text { Number of } \\
\text { parasites }\end{array}$} & \multirow{2}{*}{$\mathrm{P} \%$} & \multicolumn{2}{|c|}{ Intensity } & \multirow{2}{*}{$\begin{array}{c}\text { Abundance } \\
\mathrm{MA} \pm \mathrm{SE}\end{array}$} \\
\hline & & & Range & $\mathrm{MI} \pm \mathrm{SE}$ & \\
\hline Cestodes (cysticercoids) & 1642 & 39.2 & $1-11$ & $1.68 \pm 0.04$ & $0.660 \pm 0.02$ \\
\hline Confluaria podicipina (Szymanski, 1905) & 1471 & 34.9 & $1-11$ & $1.69 \pm 0.04$ & $0.592 \pm 0.02$ \\
\hline Hymenolepis (s. l.) californicus Young, 1950 & 168 & 6.5 & $1-2$ & $1.04 \pm 0.02$ & $0.068 \pm 0.01$ \\
\hline Wardium sp. & 2 & 0.1 & 1 & $1.00 \pm 0.00$ & $0.001 \pm 0.00$ \\
\hline Fuhrmannolepis averini Spassky et Yurpalova, 1967 & 1 & 0.04 & 1 & 1.00 & $0.001 \pm 0.00$ \\
\hline \multicolumn{6}{|l|}{ Nematodes (larvae) } \\
\hline Acuariidae gen. sp. & 97 & 3.8 & $1-2$ & $1.03 \pm 0.02$ & $0.039 \pm 0.00$ \\
\hline Overall infection & 1739 & 40.7 & $1-11$ & $1.72 \pm 0.04$ & $0.699 \pm 0.02$ \\
\hline
\end{tabular}

\section{RESULTS}

\section{General parameters of infection}

Five helminth species were identified in 1011 infected individuals out of 2487 brine shrimp examined. A total of 1739 parasite specimens, including 1642 cestode cysticercoids and 97 nematode larvae, was registered. The intensity of helminth infection was 1-11 parasites. The total values of MI and MA were $1.72 \pm 0.04$ and $0.699 \pm 0.02$, respectively (Table 1).

Four species of cyclophyllidean cestodes were recorded in Artemia franciscana in GSL. Three of these belong to the family Hymenolepididae, i.e. Confluaria podicipina (Szymanski, 1905) (adults parasitic in grebes), Hymenolepis (s. l.) californicus (adults parasitic in gulls) and Wardium sp. (majority of the species of this genus are parasitic in aquatic birds). The fourth cestode species belongs to the family Dilepididae, Fuhrmannolepis averini Spassky et Yurpalova, 1967, a parasite found in phalaropes. Confluaria podicipina was the most prevalent and abundant helminth species in our samples (Table 1). The fifth helminth taxon was a nematode species (third-stage larva) of the family Acuariidae, further referred to as 'Acuariidae gen. sp.'.

The $\mathrm{P} \%$, MI and MA of cestode infections were much higher than those for the nematode infections $(p<0.001)$. Thus, the intensity of cestode infections ranged between 1-11 cysticercoids while only 1-2 nematode larvae per individual were detected (Table 1). Host thorax was the preferential site for all helminth species recorded.

\section{Systematic survey of helminth larvae}

\section{Cestodes}

Family Hymenolepididae Ariola, 1899

Confluaria podicipina (Szymanski, 1905)

Figs. 1, 4A

Specimens studied: ex Artemia franciscana, GSL, Antelope Island Causeway, 29 September 2009, 17 cysticercoids, measured in glycerol mounts; 5 cysticercoids isolated and mounted in Berlese's medium.

Remarks. We do not provide a description of cysticercoids of $C$. podicipina from GSL because their morphology (Figs. 1, 4A) corresponds to that of cysticercoids from A. parthenogenetica (diploid populations) in Spain (Geor- giev et al. 2005). Cysts and scoleces of the cysticercoids from Spain are slightly larger compared to specimens from GSL (Table 2), probably because they have been measured from isolated cysticercoids in Berlese's medium (Georgiev et al. 2005) that may affect the size of the muscular organs and cysts but not of rostellar hooks (specimens from GSL have been measured in glycerol mounts). Often, cysticercoids of this species were distinctly larger than other individuals (Fig. 1A,C,D), most frequently when adult $A$. franciscana carried 2-3 cysticercoids. The difference between larger specimens and the majority of cysticercoids was mainly in the size of the external envelope formed by the cercomer.

Maksimova (1981) examined the life cycle of C. podicipina after experimental infection of a species of Artemia from Kazakhstan and described metacestodes at different degree of development stage. She reported similar differences between young cysticercoids on the $10^{\text {th }}$ day post infection (DPI) and fully developed cysticercoids ( $\left.16^{\text {th }} \mathrm{DPI}\right)$. Young larvae had no fully developed cercomer and external envelopes; they were smaller in size, even their rostellar hooks were slightly shorter in comparison with the hooks of the fully developed larvae $(20 \mu \mathrm{m} v s 22 \mu \mathrm{m}$, respectively). In addition, Maksimova (1981) mentioned that between $13^{\text {th }}$ and $15^{\text {th }}$ days post-infection, both smaller and fully developed cysticercoids were recorded in the same host individual.

During the present study, we found cysticercoids of various sizes, including some specimens with intermediate measurements. Despite the differences in the measurements of the external envelope, the morphology of all cysticercoids and the shape of their rostellar hooks were similar (Fig. 4A). On this basis, we identify all cysticercoids of the genus Confluaria from GSL as C. podicipina.

Confluaria podicipina has been recorded in North America in the horned grebe Podiceps auritus (Linnaeus) and in the eared grebe $P$. nigricollis Brehm (known outside America as black-necked grebe) from Alberta (Canada) (Stock and Holmes 1987).

\section{Hymenolepis (sensu lato) californicus Young, 1950} Figs. 2A-E, 4B,C,E

Specimens studied: ex Artemia franciscana, GSL, Antelope Island Causeway, July 2009, 26 cysticercoids; 

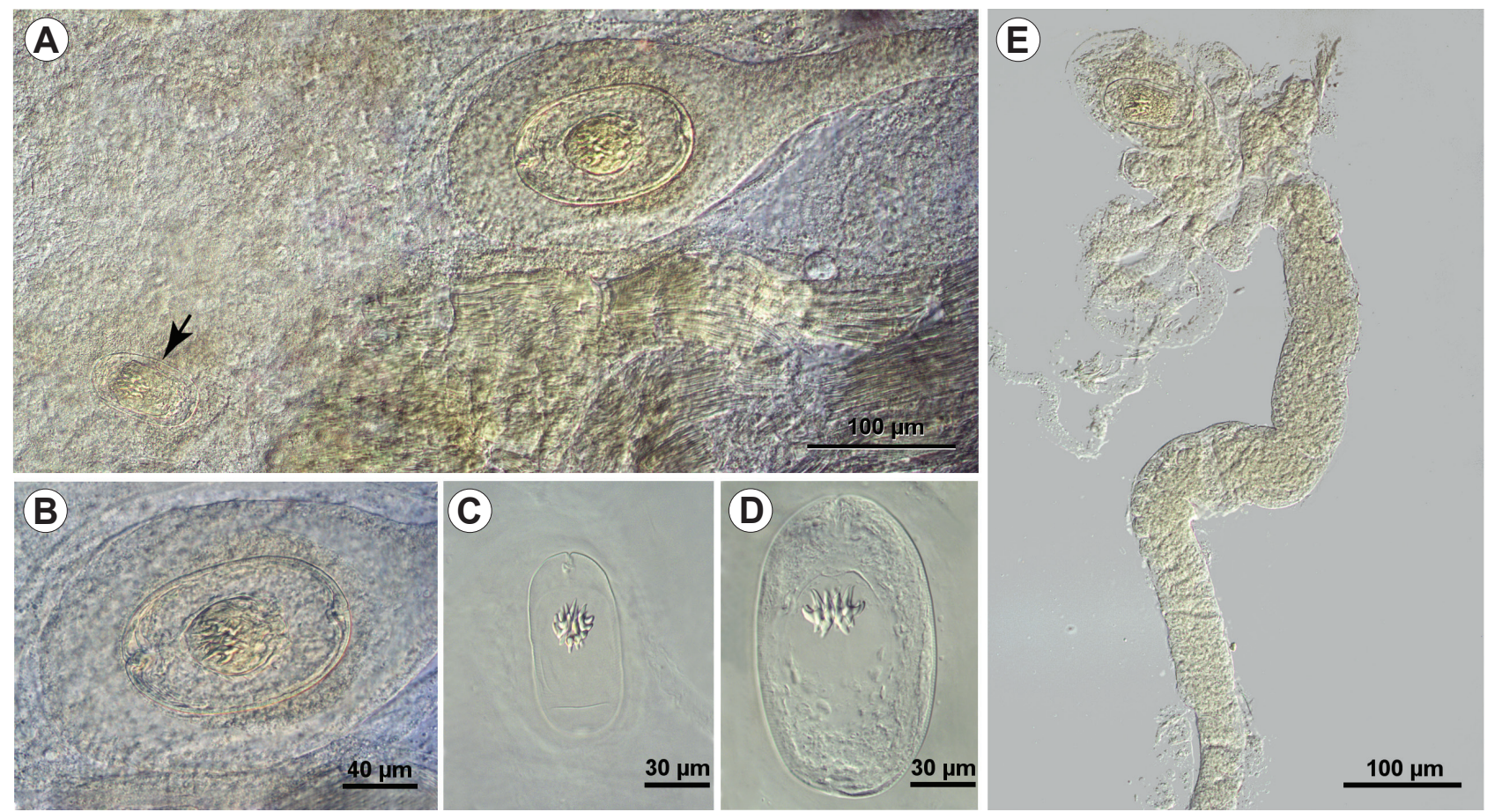

Fig. 1. Confluaria podicipina (Szymanski, 1905) from Artemia franciscana Kellogg, Great Salt Lake, Utah, USA. A - two cysticercoids at different stages of development, note the smaller cysticercoid (arrow); temporary glycerol mount; B - fully developed cysticercoid (temporary glycerol mount); C, D - isolated internal cysts at different stages of development (mounts in Berlese's medium); $\mathbf{E}$ - isolated cysticercoid with unpacked cercomer (mounts in Berlese's medium).

Table 2. Metrical data of cysticercoids of Confluaria podicipina (Szymanski, 1905) from Artemia spp. from various hosts and localities.

\begin{tabular}{|c|c|c|c|c|c|c|c|c|}
\hline & Host & 'A. salina' & \multirow{2}{*}{\multicolumn{3}{|c|}{$\begin{array}{c}\text { A. parthenogenetica } \\
\text { Odiel (Spain) }\end{array}$}} & \multirow{2}{*}{\multicolumn{3}{|c|}{$\frac{\text { A. franciscana }}{\text { Utah (USA) }}$}} \\
\hline & Locality & Tengiz Lake (Kazakhstan) & & & & & & \\
\hline & References & Maksimova (1981) & \multicolumn{3}{|c|}{ Georgiev et al. (2005) } & \multicolumn{3}{|c|}{ Present study } \\
\hline & & Range & Range & Mean & $\mathrm{n}$ & Range & Mean & $\mathrm{n}$ \\
\hline \multirow[t]{2}{*}{ External capsule } & length & $147-170$ & $195-255$ & 215 & 9 & $144-313$ & 212 & 15 \\
\hline & width & 105 & $135-204$ & 152 & 9 & $72-192$ & 118 & 15 \\
\hline \multirow[t]{2}{*}{ Cyst } & length & $103 *$ & $93-147$ & 121 & 12 & $72-143$ & 106 & 17 \\
\hline & width & $53 *$ & $47-87$ & 73 & 12 & $36-89$ & 61 & 17 \\
\hline \multirow[t]{2}{*}{ Scolex } & length & 60 & $72-104$ & 92 & 12 & $38-52$ & 48 & 15 \\
\hline & width & 38 & $38-72$ & 59 & 12 & $25-47$ & 37 & 15 \\
\hline Suckers & diameter & $20-25$ & $26-32$ & 28 & 10 & $21-26$ & 22 & 6 \\
\hline Rostellum & length & 38 & $42-47$ & 46 & 7 & $23-31$ & 27 & 10 \\
\hline \multirow[t]{4}{*}{ Rostellar hooks } & total length & 22 & $21-24$ & 22 & 12 & $19-21$ & 20 & 11 \\
\hline & blade & - & - & - & - & 11 & - & 11 \\
\hline & handle & - & - & - & - & $3-5$ & 4 & 11 \\
\hline & guard & - & - & - & - & $5-6$ & 6 & 11 \\
\hline
\end{tabular}

* measurements based on fig. 2D of Maksimova (1981).

GSL Ogden Bay, August 2009, 14 cysticercoids. Comparative material: ex Larus californicus Lawrence, California (USNPC No. 46488), two slides with paratypes of Hymenolepis californicus specimens, stained and mounted in Canada balsam.

Description of cysticercoids: Cercocysticercoid. Cyst oval to lemon-shaped, 164-247 × 108-171 $(195 \times$ $140, \mathrm{n}=39$ ), with thick wall consisting of three layers (Figs. 2A-C, 4E); transparent outer envelope not seen. Scolex almost round, 74-108 (91, $\mathrm{n}=13)$ long, with maximum width $72-99(86, \mathrm{n}=13)$ at level of suckers. Rostrum short, conically tapering. Suckers oval, with weakly-de- veloped musculature, unarmed, 32-40 $(36, \mathrm{n}=37)$ in diameter. Rostellar sheath deep, thick-walled, crossing level of posterior margins of suckers, 58-81 × 36-50 $(66 \times 42$, $\mathrm{n}=11$ ). Rostellum thick-walled, with apical enlargement and conically-tapering posterior part; $32-54(41, \mathrm{n}=11)$ long and 25-36 (30, $\mathrm{n}=11)$ wide at apical region. Rostellum invaginable. Rostellar hooks 10 in number, almost aploparaksoid in shape (Figs. 2D,E, 4B); blade long, thin, straight; guard shorter than blade; handle distinct, short; total length of hooks $18-20(19, \mathrm{n}=18)$, length of blade $10-12(11, \mathrm{n}=18)$, handle $4-5(4, \mathrm{n}=18)$ and guard $6-8$ $(7, \mathrm{n}=18)$. Cercomer (Figs. 2A,B, 4E) with maximum 

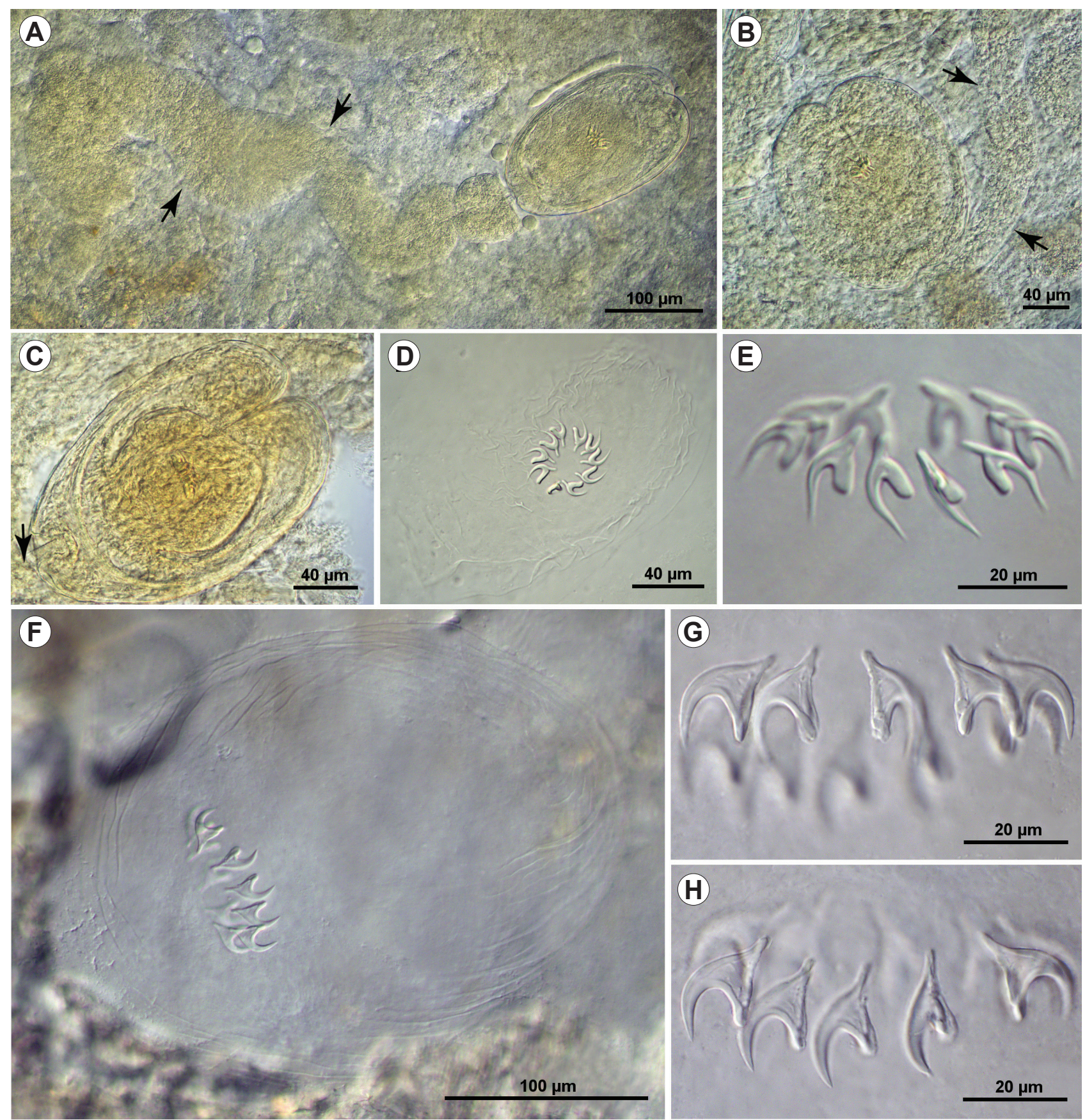

Fig. 2. Hymenolepis (sensu lato) californicus Young, 1950 (A-E) and Wardium sp. (F-H) from Artemia franciscana Kellogg, Great Salt Lake, Utah, USA. A-C - cysticercoids with fragments of cercomer (arrows), temporary glycerol mount; D, E, G, H - rostellar hooks; $\mathbf{F}$ - isolated cysticercoid (mount in Berlese's medium).

width 41-76 (43, $\mathrm{n}=14)$; entire cercomer not isolated and not measured; maximum length of fragments $0.8-1.8 \mathrm{~mm}$ $(1.2 \mathrm{~mm}, \mathrm{n}=4)$.

Observations on paratypes of $\boldsymbol{H}$. californicus: For the morphology of rostellar hook, see Fig. 4C. Measurements of rostellar hooks: total length $19(\mathrm{n}=5)$, blade $11(\mathrm{n}=5)$, handle $4(\mathrm{n}=5)$, guard $7-8(7, \mathrm{n}=5)$.

Remarks. The cysticercoids from $A$. franciscana from GSL possess rostellar hooks with almost aploparaksoid shape. They can be distinguished from typical aploparaksoid hooks by their short but distinct handle. A group of hymenolepidids from birds (mainly gulls) using bran- chiopods as intermediate host possess rostellar hooks of similar shape to those recorded in the present study. Most of them have been placed in the genus Wardium Mayhew, 1925 and, later, five of them have been separated to form the genus Branchiopodataenia Bondarenko et Kontrimavichus, 2004 (see Bondarenko and Kontrimavichus 2004a). None of the cysticercoids of Branchiopodataenia spp. (see Bondarenko and Kontrimavichus 2004b) has rostellar hooks identical to those of the present material.

We have compared the present cysticercoids with three hymenolepidids from gulls possessing similar hooks and known to have life-cycles that include branchiopods as in- 
termediate hosts. These are Wardium stellorae (Deblock, Biguet et Capron, 1960), Hymenolepis californicus and H. (s. l.) fusus (Krabbe, 1869). Cysticercoids of W. stellorae from Palaearctic Artemia spp. (Maksimova 1986, Georgiev et al. 2005, 2007) have rostellar hooks $23 \mu \mathrm{m}$ long vs 18-20 $\mu \mathrm{m}$ (av. $19 \mu \mathrm{m})$ in specimens from GSL; the blades of the hooks of $W$. stellorae are slender, longer, with slightly curved ends, which also differs them from the present material.

Hymenolepis fusus was described as Taenia fusus from Larus hyperboreus Gunnerus from Greenland and L. ridibundus Linnaeus from Germany (Krabbe 1869). It has been revealed that the type-specimens belonged to two species; the type-specimens from L. hyperboreus were identified as Branchiopodataenia arctowskii (Jarecka et Ostas, 1984) whereas the types from L. ridibundus were considered as representative for Hymenolepis (s. l.) fusus (see Bondarenko and Petkevichiute 1998, Bondarenko and Kontrimavichus 2004a). Upon re-examination of these latter specimens, Bondarenko and Petkevichiute (1998) noted aploparaksoid-like rostellar hooks with length 17-18 $\mu \mathrm{m}$ and distinct handles ( $3 \mu \mathrm{m}$ long), thus differing from the present material. Cysticercoids of $H$. (s. l.) fusus from A. 'salina' in Kazakhstan (Maksimova 1987) have shape of hooks (see figs. 1B, E of Maksimova 1987) characterised by less-expressed handle and blade situated at angle to the guard (compared to almost parallel blade and guard in the present material).

Young (1950) described Hymenolepis californicus from Larus californicus (type-host) and L. delawarensis Ord in California. Upon re-examination of paratypes of this species, we found identical shape and size of the rostellar hooks with the hooks of the present cysticercoids (Fig. 4B,C). Thus, we identify the cysticercoids described above as H. (s.l.) californicus. Furthermore, the GSL population of California gulls is abundant and represents the largest breeding population of this species in the world (Manning and Paul 2003). In the present study, we follow the suggestion of Bondarenko and Kontrimavichus (2004a) who regarded this species as a member of Hymenolepis Weinland, 1858 (sensu lato), pending further studies on its strobilar morphology.

Young (1952) described the larva of H. (s.l.) californicus from Artemia 'salina' from Mono Lake and salt pools near Chula Vista, California. The length of the larva was described as varying between $73 \mu \mathrm{m}$ and $256 \mu \mathrm{m}$ and the rostellar hooks were 8-17 $\mu \mathrm{m}$ long. Young (1952) considered this variability as "undoubtedly developmental". In addition, he mentioned the variation in the shape of the cysts and their envelopes. Some of them have been found "to lie free in the body of the shrimp" whereas others have been surrounded by a thick sac with a very long, spirally coiled tail (7-20 mm long, see fig. 2 of Young 1952). The latter features resemble the morphology of the cysticercoids of Confluaria podicipina. Therefore, we believe that the samples of Young (1952) contained cysticercoids of both $C$. podicipina and $H$. (s. l.) californicus. The high levels of infection with cysticercoids of $C$. podicipina observed by Young (1952) and its seasonal dynamics are not unexpected since Mono Lake is one of the sites (together with GSL) where nearly the entire North-American population of Podiceps nigricollis concentrates for several months during migrations (Jehl and Johansson 2002).

\section{Wardium sp. \\ Figs. 2F-H, 4D,F \\ Specimens studied: ex Artemia franciscana, GSL} Antelope Island Causeway, 8 July 2009, 2 cysticercoids, mounted in Berlese's medium.

Description of cysticercoids (metrical data based on specimens mounted in Berlese's medium): Cercocysticercoid. Cyst lemon-shaped, thick-walled (Figs. 2F, 4F), 236-291 × 197-214 $(n=2)$. Scolex oval, with wide, conically tapering anterior part; length $136(\mathrm{n}=1)$ and maximum width $109(\mathrm{n}=1)$ at level of suckers. Suckers oval, with weakly-developed musculature, unarmed, with diameter 44-50 (47, $\mathrm{n}=4)$. Rostellar sheath deep, thin-walled, $106 \times 53(n=1)$, crossing level of posterior margins of suckers. Rostellum thick-walled, with apical enlargement and conically-tapering posterior part; 68 long, 52 wide at apical part $(\mathrm{n}=1)$. Rostellar hooks 10 in number, with aploparaksoid-like shape (Figs. 2G,H, 4D); blade sickleshaped, slightly longer than guard; handle distinct but very short; well-developed epiphyseal thickening comprising base of hook from handle to tip of guard; total length of hooks 24-26 (25, $\mathrm{n}=12)$, length of blade 12-14 (13, $\mathrm{n}=12)$, length of base $18-19(18, \mathrm{n}=12)$, handle $3-4$ $(4, \mathrm{n}=12)$ and guard 9-11 $(10, \mathrm{n}=12)$; distance between handle-tip and guard-tip 9-11 $(10, \mathrm{n}=12)$. Cysticercoid with complete cercomer not available; maximum width of fragments of cercomer 45-61 $(n=2)$.

Remarks. Judging by the aploparaksoid shape of rostellar hooks, the cysticercoids described above resemble species of Branchiopodataenia and Wardium. With a total length of hooks 24-26 $\mu \mathrm{m}$ and the presence of welldeveloped epiphyseal thickening of the base of hook, the cysticercoids from GSL differ from all Branchiopodataenia spp. described by Bondarenko and Kontrimavichus (2004a,b). Moreover, except for B. gvozdevi (Maksimova, 1988), which has large hooks, the remaining four species of Branchiopodataenia have hooks less than $20 \mu \mathrm{m}$ long (Bondarenko and Kontrimavichus 2004a,b). None of the species in this genus is known to possess epiphyseal thickenings of the rostellar hooks. Among all species of Wardium, only a few are similar to our specimens in terms of shape and size of rostellar hooks (Spasskaya 1966, Bondarenko and Kontrimavichus 2006). They are mainly parasites of Charadriiformes, rarely of Anseriformes. Our specimens could not belong either to $W$. fryei Mayhew, 1925, a widespread parasite of gulls in the Holarctic, using annelids as intermediate hosts (Bondarenko 1997), or to W. aequabilis (Rudolphi, 1810), a parasite of Anseriformes in the Palaearctic Region, using ostracods as intermediate hosts (Jarecka 1960).

Several Wardium spp. have 22-30 $\mu \mathrm{m}$ long rostellar hooks, thus resembling cysticercoids from GSL but differing from them by the shape of the hooks. These are W. amphitricha (Rudolphi, 1819), W. cirrosa (Krabbe, 1869), W. capellae (Baer, 1940) and W. longosacco (Joy- 
eux et Baer, 1939). The hooks of these species are without epiphyseal thickenings, distinct handles and blades longer than guards. A few species have rostellar hooks with epiphyseal thickening and shape similar to that of the cysticercoids from GSL but differing in hook length. These are W. canarisi Kinsella et Deblock, 2000 (hooks 19-21 $\mu \mathrm{m}$ long), W. chaunense Bondarenko et Kontrimavichus, 1977 (43-45 $\mu \mathrm{m})$ and $W$. porale (Meggitt, 1927) (22 $\mu \mathrm{m})$ (see Bondarenko and Kontrimavichus 2006).

The rostellar hooks of the cysticercoids from GSL are similar to those of $W$. neranium Belogurov et Zueva, 1967 and W. villosocirrus (Deblock et Rausch, 1967). So far, $W$. neranium has been found in Pluvialis squatarola (Linnaeus) from the Russian Far East. It has rostellar hooks 25-30 $\mu \mathrm{m}$ long, with well-developed epiphyseal thickening of the handle and guard. However, the distance between the blade-tip and the guard-tip is smaller compared to the hooks of the present material, i.e. 5-7 $\mu \mathrm{m}$ in $W$. neranium (see figs 129, 130 of Bondarenko and Kontrimavichus 2006) vs 9-11 $\mu \mathrm{m}$ in the specimens from Utah.

Wardium villosocirrus from Limosa haemastica (Linnaeus) in Alaska (Deblock and Rausch 1967, Bondarenko and Kontrimavichus 2006) has rostellar hooks 23-24 $\mu \mathrm{m}$ long, with blade $12 \mu \mathrm{m}$ long and a guard almost as long as blade. However, the shape of the hooks of $W$. villosocirrus is different (see fig. 142 of Bondarenko and Kontrimavichus 2006), with a straight blade or a blade slightly curved away from the guard. In contrast, the hooks of the specimens from GSL have a sickle-shaped blade, curved in direction to the guard (Fig. 4D).

Previous studies on cestodes from charadriiforms in the Nearctic have revealed 12 Wardium spp. (Table S2) but none of them can be matched with the present materials.

Family Dilepididae Railliet et Henry, 1909

Fuhrmannolepis averini Spassky et Yurpalova, 1967 Figs. 3A,B, 4G,H

Specimens studied: ex Artemia franciscana, GSL Saltair Marina, September 2009, 1 cysticercoid, mounted in Berlese's medium together with the brine shrimp.

Description of cysticercoid: Monocysticercoid. Outer capsule very thick, oval, brownish, with granular contents (Fig. 3A), $291 \times 277(n=1)$; when compressed, outer capsule breaks down into cercomer fragments. Internal cyst oval, $219 \times 206(\mathrm{n}=1)$ (Fig. 4G). Scolex almost conical, $109 \times 125(\mathrm{n}=1)$, with slightly protruded anterior part. Suckers round, muscular, 45-61 $(53, \mathrm{n}=4)$ in diameter. Rostellum retractile, elongated, $97 \times 25(\mathrm{n}=1)$, with muscular walls and apical enlargement. Rostellar sheath deep, $107 \times 44(\mathrm{n}=1)$, passing beyond posterior margins of suckers. Rostellar hooks 13 in number, wrench-shaped, arranged in single crown (Figs. 3B, 4H). Each hook with thin, almost straight blade, well-developed guard (shorter than blade) and long straight handle (Fig. 4H); total length of hooks $11-12(12, n=3)$, length of blade $4(n=3)$, length of base $8(n=3)$, handle $7(n=3)$.

Remarks. The cysticercoids of the family Dilepididae developing in brine shrimps belong to the monocysticer- coid type as defined by Chervy (2002). With the presence of 13 wrench-shaped rostellar hooks, the cysticercoid found in A. franciscana in Utah is most similar to Fuhrmannolepis averini, which is a parasite specific to phalaropes. This species has been described from the red-necked phalarope Phalaropus lobatus (Linnaeus) (type-host) and the red phalarope $P$. fulicarius (Linnaeus) in Kamchatka, Russia (Spassky and Yurpalova 1967).

Cysticercoids of F. averini have been recorded in Daphnia pulex Leydig (see Tomilovskaya 1975) and in Artemia 'salina' (see Maksimova 1977). The shape of the hooks described by Tomilovskaya (1975) differs from that in adult worm (Spassky and Yurpalova 1967, Spassky et al. 1968, Maksimova 1977). Therefore, this record needs confirmation. Adult $F$. averini from $P$. lobatus and cysticercoids from brine shrimps from Kazakhstan were described in detail by Maksimova (1977). She characterised the cysticercoid as having a brownish outer capsule, $210 \times 160 \mu \mathrm{m}$; internal cyst $180 \times 140 \mu \mathrm{m} ; 16$ wrench-shaped rostellar hooks with total length 13-14 $\mu \mathrm{m}$. Our results are in agreement with Maksimova's (1977) description in both morphology and metrical data except for number of hooks (13 in the present material and 16 reported from Kazakhstan). Previous records of adults of $F$. averini have demonstrated variations in the number of hooks between 12 and 14 (Spassky et al. 1968, Spasskaya and Spassky 1978).

This is the first record of $F$. averini in the Nearctic. Its presence in A. franciscana in GSL matches the high abundance of Phalaropus lobatus and P. tricolor (Vieillot) at this lake (Table S1).

\section{Nematodes}

Family Acuariidae Railliet, Henry et Sisoff, 1912

Acuariidae gen. sp.

Figs. 3C-E, 4I-K

Specimens studied: ex Artemia franciscana, GSL, Antelope Island Causeway, August 2009, ten larvae in temporary glycerol whole mounts.

Description of larvae $(\mathrm{n}=10)$ : Third-stage larvae (Figs. 3C, 4I). Body 2.07-2.89 mm (2.28 mm) long, with maximum width about mid-body, 72-98 (81). Anterior end with 2 triangular pseudolabia, each bearing 1 pair of papillae (Figs. 3D, 4J). Cordons delicate, arise dorsally and ventrally between pseudolabia, extending along outer (dorsal and ventral) side of cephalic papillae to level of 31-41 (36) from anterior extremity (Fig. 4J). Deirids spine-like, 5-6 long, situated at 70-93 (78) from anterior end. Lateral alae extend from 36-44 (39) to mid-tail (Fig. 4K). Excretory pore at 151-204 (172) from anterior end. Tail 104-130 (114) long; width at anus 29-43 (34) (Figs. 3E, 4K). Buccal cavity 71-93 (83) long, 6-7 wide. Muscular oesophagus 149-221 (185) long, 16-25 (17) wide. Glandular oesophagus 576-968 (756) long, 40-70 (52) wide. Nerve-ring at 88-112 (101) from anterior end. Cuticle thickness 2. Distance between cuticular striations 3-4. Relative length (ratio) of muscular and glandular oesophagus to body length $0.350-0.452$ (0.411). Relative length of muscular oesophagus to glandular oesophagus (ratio) 0.205-0.309 (0.248). 

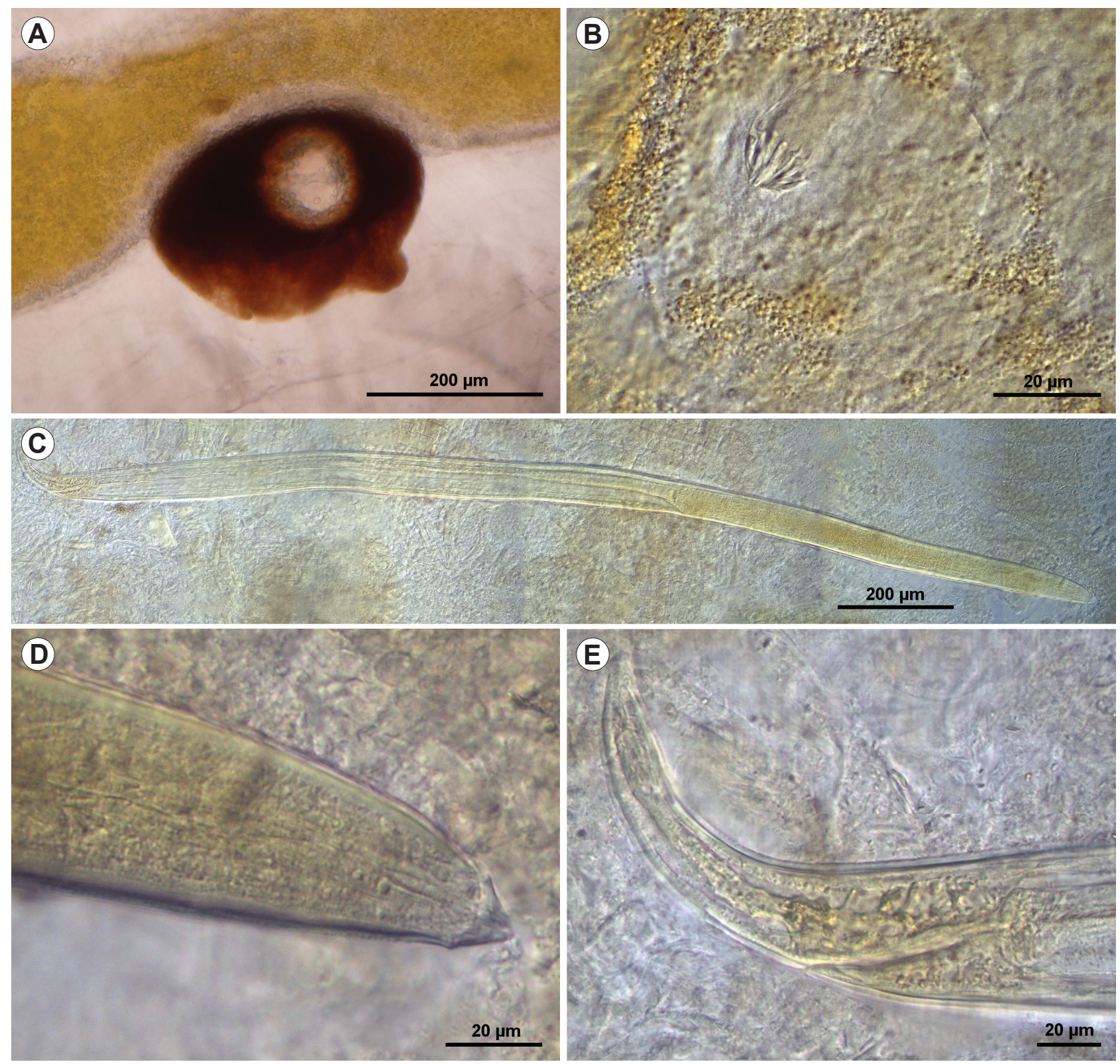

Fig. 3. Fuhrmannolepis averini Spassky et Yurpalova, 1967 (A-B) and Acuariidae gen. sp. (C-E) from Artemia franciscana Kellogg, Great Salt Lake, Utah, USA. A - monocysticercoid with outer capsule (formed by the cercomer) in the thorax of brine shrimp (temporary glycerol mount); B - isolated cysticercoid, detail of rostellar apparatus; $\mathbf{C}$ - total view of nematode larvae (temporary glycerol mount); $\mathbf{D}$ - anterior end with triangular pseudolabia; $\mathbf{E}$ - tail.

Remarks. These third-stage larvae were identified as belonging to the subfamily Acuariinae Railliet, Henry et Sisoff, 1912 (Spirurida: Acuariidae) on the basis of their morphology characterised by an oesophagus divided into muscular and glandular portions, lateral triangular pseudolabia, elongate buccal cavity and cordons arising from the bases of pseudolabia (Chabaud 1975, Anderson 2000). These larvae cannot be identified to the generic level because their morphology does not resemble that of adults and also because of the scarcity of previous studies. Larval and adult stages of this family cannot be linked on the basis of morphology only. Genera of the Acuariinae have been differentiated on the basis of the morphology of adults, which typically occupy the upper alimentary tract of birds (Chabaud 1975). Nematode larvae with similar morphol- ogy, identified as Acuariinae gen. sp., have been found in A. franciscana (see Georgiev et al. 2014) as well as in A. parthenogenetica (diploid populations) and A. salina (unpublished data) in Spain.

Considering the bird species in the area and their potential parasites of the Acuariinae, the nematode larvae described here can be distinguished by their cordons extending along the outer (dorsal and ventral) sides of the cephalic papillae from those of Cosmocephalus Molin, 1858, parasitic in grebes and gulls (Mutafchiev et al. 2010), characterised by cordons that do not extend beyond the level of cephalic papillae (Wong and Anderson 1982); from Skrjabinocerca Shikhobalova, 1930, parasitic in plovers and sandpipers (Wong and Anderson 1993), having cordons extended along the inner (lateral) side of the cephalic pa- 
A

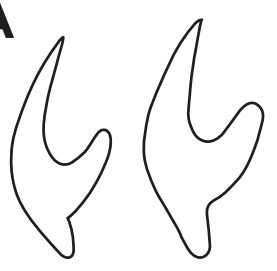

B

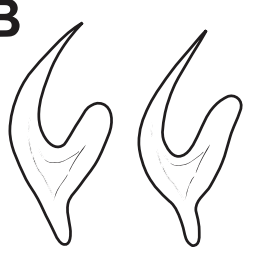

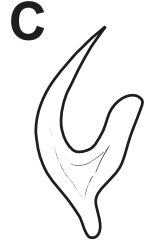
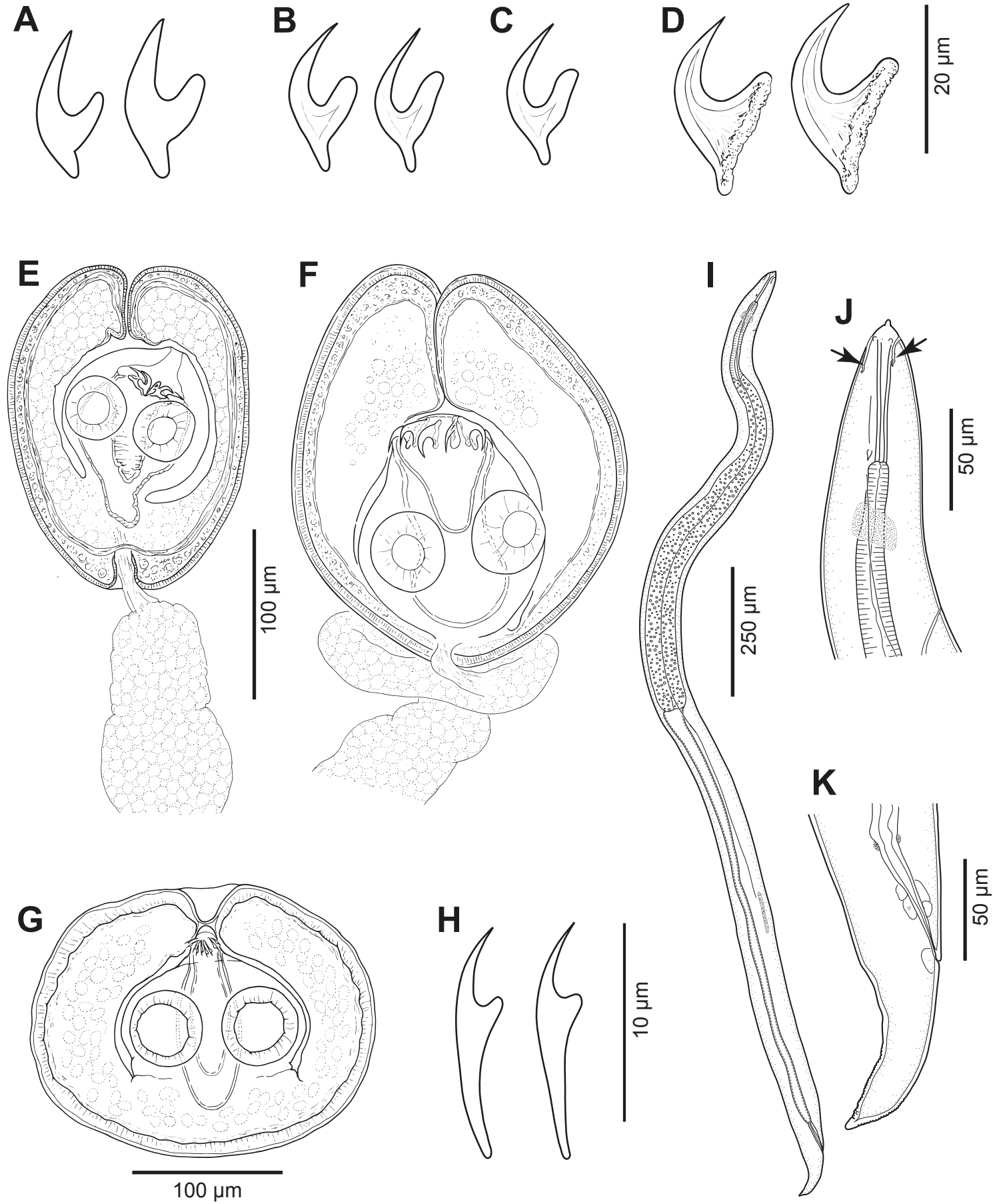

Fig. 4. Helminth larvae from Artemia franciscana Kellogg, Great Salt Lake, Utah, USA. A - hooks of Confluaria podicipina (Szymanski, 1905); B, C, E - Hymenolepis (sensu lato) californicus Young, 1950 (B - hooks of cysticercoid, C - hook of paratype specimen from Larus californicus Lawrence, $\mathbf{E}$ - cysticercoid); D, F - hooks and cysticercoid of Wardium sp.; $\mathbf{G}, \mathbf{H}$ - cysticercoid and hooks of Fuhrmannolepis averini Spassky et Yurpalova, 1967; I-K - Acuariidae gen. sp. (I - total view; J - anterior end , note cordons (arrows); $\mathbf{K}$ - tail).

pillae (Bartlett et al. 1989); from Skrjabinoclava Sobolev, 1943, parasitic in plovers, curlews, sandpipers and turnstones (Anderson and Wong 1992), having cordons anastomosing posterior to the cephalic papillae (Wong et al. 1989); from Desportesius Chabaud et Campana, 1949, mostly parasitic in herons (Wong and Anderson 1986); and Skrjabinocara Kurashvili, 1940, parasitic in cormorants (Smogorzhevskaya 1990), with larvae lacking cordons (Chabaud 1950, Wong and Anderson 1987). On the basis of the species diversity and the abundance of potential definitive hosts at GSL (Table S1), it can be speculated that the present larval nematodes may belong to the genera Chevreuxia Seurat, 1918, parasitic mainly in stilts and avocets (Smogorzhevskaya 1990), Decorataria Sobolev in Skryabin, Shikhobalova et Sobolev, 1949, parasitic in grebes (Mutafchiev and Georgiev 2008) or Echinuria Soloviev, 1912, parasitic in grebes, gulls and ducks (Baruš et al. 1978, Smogorzhevskaya 1990). All these genera have 
Table 3. Spatial variations of helminth infections in Artemia franciscana from the Great Salt Lake. Differences between sites were tested by Chi-squared $\left(\chi^{2}\right)$ or Fisher exact test (for prevalence) and Kruskal-Wallis test [K-W $\left.(\mathrm{H})\right]$ (for intensity and abundance).

\begin{tabular}{|c|c|c|c|c|c|c|}
\hline Helminth infection & SM & AI & AIC & OB & $\chi^{2}$ & K-W (H) \\
\hline No. of Artemia individuals examined & 693 & 545 & 713 & 536 & - & - \\
\hline No. of Artemia individuals infected & 229 & 228 & 387 & 167 & - & - \\
\hline \multicolumn{7}{|l|}{ Cestodes (overall infection) } \\
\hline $\mathrm{P} \%$ & $32.6^{\mathrm{a}}$ & $41.1^{\mathrm{b}}$ & $51.3^{\mathrm{c}}$ & $29.7^{\mathrm{a}}$ & $77.928^{* *}$ & - \\
\hline $\mathrm{MI} \pm \mathrm{SE}$ & $1.71 \pm 0.10^{\mathrm{a}}$ & $1.48 \pm 0.06^{\mathrm{a}}$ & $1.90 \pm 0.07^{\mathrm{b}}$ & $1.43 \pm 0.06^{\mathrm{a}}$ & - & $23.151^{* *}$ \\
\hline Range of intensity & $1-11$ & $1-7$ & $1-9$ & $1-4$ & - & - \\
\hline $\mathrm{MA} \pm \mathrm{SE}$ & $0.56 \pm 0.04^{\mathrm{a}}$ & $0.61 \pm 0.04^{b}$ & $0.98 \pm 0.05^{\mathrm{c}}$ & $0.42 \pm 0.03^{\mathrm{a}}$ & - & $91.657^{* *}$ \\
\hline \multicolumn{7}{|l|}{ Confluaria podicipina } \\
\hline $\mathrm{P} \%$ & $31.7^{\mathrm{a}}$ & $40.6^{\mathrm{b}}$ & $39.4^{\mathrm{b}}$ & $27.4^{\mathrm{a}}$ & $30.241^{* *}$ & - \\
\hline $\mathrm{MI} \pm \mathrm{SE}$ & $1.72 \pm 0.10^{\mathrm{a}}$ & $1.49 \pm 0.06^{\mathrm{b}}$ & $1.97 \pm 0.09^{\mathrm{ac}}$ & $1.44 \pm 0.06^{\mathrm{b}}$ & - & $16.743 * *$ \\
\hline $\mathrm{MA} \pm \mathrm{SE}$ & $0.55 \pm 0.04^{\mathrm{a}}$ & $0.60 \pm 0.04^{\mathrm{b}}$ & $0.78 \pm 0.05^{\mathrm{b}}$ & $0.39 \pm 0.03^{\mathrm{a}}$ & - & $32.957 * *$ \\
\hline \multicolumn{7}{|l|}{ Hymenolepis (s. l.) californicus } \\
\hline $\mathrm{P} \%$ & $0.7^{\mathrm{a}}$ & $0.6^{\mathrm{a}}$ & $19.2^{\mathrm{c}}$ & $3.0^{\mathrm{b}}$ & $271.391^{* *}$ & - \\
\hline $\mathrm{MI} \pm \mathrm{SE}$ & 1.00 & 1.00 & $1.05 \pm 0.02$ & 1.00 & - & $n s$ \\
\hline $\mathrm{MA} \pm \mathrm{SE}$ & $0.01 \pm 0.003^{\mathrm{a}}$ & $0.01 \pm 0.003^{\mathrm{a}}$ & $0.20 \pm 0.02^{c}$ & $0.03 \pm 0.01^{\mathrm{b}}$ & - & $271.611 * *$ \\
\hline \multicolumn{7}{|l|}{ Wardium sp. } \\
\hline $\mathrm{P} \%$ & 0.3 & 0 & 0 & 0 & $n s$ & - \\
\hline $\mathrm{MI} \pm \mathrm{SE}$ & 1.00 & 0 & 0 & 0 & - & no test \\
\hline $\mathrm{MA} \pm \mathrm{SE}$ & $0.003 \pm 0.002$ & 0 & 0 & 0 & - & $n s$ \\
\hline \multicolumn{7}{|l|}{ Fuhrmannolepis averini } \\
\hline $\mathrm{P} \%$ & 0.1 & 0 & 0 & 0 & $n s$ & - \\
\hline $\mathrm{MI} \pm \mathrm{SE}$ & 1.00 & 0 & 0 & 0 & - & no test \\
\hline $\mathrm{MA} \pm \mathrm{SE}$ & $0.001 \pm 0.001$ & 0 & 0 & 0 & - & $n s$ \\
\hline \multicolumn{7}{|l|}{ Acuariidae gen. sp. } \\
\hline $\mathrm{P} \%$ & $1.6^{\mathrm{a}}$ & $1.7^{\mathrm{a}}$ & $8.4^{\mathrm{b}}$ & $2.6^{\mathrm{a}}$ & $60.083^{* *}$ & - \\
\hline $\mathrm{MI} \pm \mathrm{SE}$ & 1.00 & 1.00 & $1.05 \pm 0.03$ & 1.00 & - & $n s$ \\
\hline Range of intensity & 1 & 1 & $1-2$ & 1 & - & - \\
\hline $\mathrm{MA} \pm \mathrm{SE}$ & $0.02 \pm 0.005^{\mathrm{a}}$ & $0.02 \pm 0.005^{\mathrm{a}}$ & $0.09 \pm 0.01^{\mathrm{b}}$ & $0.03 \pm 0.007^{\mathrm{a}}$ & - & $60.201^{* *}$ \\
\hline Helminth parasites & 397 & 341 & 760 & 241 & - & - \\
\hline $\mathrm{P} \%$ & $33.0^{\mathrm{a}}$ & $41.8^{\mathrm{b}}$ & $54.3^{\mathrm{c}}$ & $31.2^{\mathrm{a}}$ & $91.838 * *$ & - \\
\hline $\mathrm{MI} \pm \mathrm{SE}$ & $1.73 \pm 0.10^{\mathrm{a}}$ & $1.50 \pm 0.06^{\mathrm{a}}$ & $1.96 \pm 0.07^{\mathrm{b}}$ & $1.44 \pm 0.05^{\mathrm{a}}$ & - & $32.679 * *$ \\
\hline Range of intensity & $1-11$ & $1-7$ & $1-9$ & $1-4$ & - & - \\
\hline $\mathrm{MA} \pm \mathrm{SE}$ & $0.57 \pm 0.05^{\mathrm{a}}$ & $0.63 \pm 0.04^{\mathrm{b}}$ & $1.07 \pm 0.05^{\mathrm{c}}$ & $0.45 \pm 0.03^{\mathrm{a}}$ & - & $112.012 * *$ \\
\hline
\end{tabular}

Significant differences are shown; $* * \mathrm{p}<0.001 ; n s-$ not-significant; no test - test was not possible because the species was recorded in one site only. Different superscript letters denote statistically significant differences after Bonferroni correction. $\mathrm{P} \%$ - prevalence; $\mathrm{MI} \pm \mathrm{SE}-\mathrm{mean}$ intensity; $\mathrm{MA} \pm \mathrm{SE}$ - mean abundance; SM - Saltair Marina; AI - Antelope Island; AIC - Antelope Island Causeway; OB - Ogden Bay.

unknown or poorly studied life-cycles and undescribed (or inadequately characterised) morphology of larval stages (Skryabin et al. 1965, Anderson 2000).

\section{Spatial and temporal variations of helminth infections}

The helminth community in brine shrimps at all sites consisted mainly of cestodes ( $>90 \%)$ and nematodes. Two of the four cestode species, C. podicipina and $H$. (s. l.) californicus, were recorded at all sites. The other two, Wardium sp. and $F$. averini, were found only at SM and had a low RA $(0.5 \%$ and $0.2 \%$, respectively). The grebe parasite $C$. podicipina was the most prevalent and abundant cestode species at all sites, with RA between 79.3\% (at AIC) and 99.1\% (at AI) of the total number of cysticercoids.

Nematode infections had significantly higher P\% and MA at AIC (Table 3). There were no significant differences for the MI of nematode larvae between sites.

For the overall cestode infections, $\mathrm{P} \%$, MI and MA varied among sites, registering significantly highest values at AIC and the lowest values at OB (Table 3). Prevalence of the gull cestode $H$. (s. l.) californicus was the highest at
AIC followed by $\mathrm{OB}$ and was lower than $1 \%$ at SM and $\mathrm{AI}$; no spatial variations in MI were found for this cestode. For C. podicipina, $\mathrm{P} \%$ was highest at $\mathrm{AI}$ and $\mathrm{MI}$ was higher at AIC (Table 3).

Monthly differences in cestode and nematode infections for each site were analysed separately (Table 4). Cysticercoids were recorded in all 12 samples while nematodes were absent in the June sample at AI and the September sample at AIC (Table 4). The temporal infection dynamics within sites followed a common pattern, i.e. the variations of the overall cestode infection followed the variations of the most abundant species (C. podicipina). The highest $\mathrm{P} \%$ of cestodes was recorded in the last month studied at each site (Table 4).

We observed differing seasonal trends of infection descriptors. Two of the sites (AI and OB) were characterised with the lowest values of $\mathrm{P} \%$ and MA of $C$. podicipina and the overall cestode infection at the middle of the sampling period, i.e. in July (Table 4). At AIC, where samples were collected between July and September, the minimum values of $\mathrm{P} \%$ and MA of the overall cestode infection were in August. SM was the only site exhibiting a trend of gradual 
Table 4. Temporal variations of helminth infections in Artemia franciscana Kellogg from Great Salt Lake. Differences between months were tested with Chi-squared $\left(\chi^{2}\right)$ or Fisher exact test (for prevalence) and Kruskal-Wallis [K-W (H)] (for intensity and abundance).

\begin{tabular}{|c|c|c|c|c|c|c|c|}
\hline & & June & July & August & September & $\chi^{2}$ & K-W (H) \\
\hline Saltair Marina & & - & $\mathrm{n}=147$ & $\mathrm{n}=230$ & $\mathrm{n}=316$ & & \\
\hline \multirow[t]{3}{*}{ C.p. } & $\mathrm{P} \%$ & - & $7.5^{\mathrm{a}}$ & $37.0^{\mathrm{b}}$ & $39.2^{\mathrm{b}}$ & $51.011 * *$ & \\
\hline & $\mathrm{MI} \pm \mathrm{SE}$ & - & $1.55 \pm 0.25^{\mathrm{ab}}$ & $1.27 \pm 0.07^{\mathrm{a}}$ & $2.04 \pm 0.17^{b}$ & & $15.570 * *$ \\
\hline & $\mathrm{MA} \pm \mathrm{SE}$ & - & $0.12 \pm 0.04^{\mathrm{a}}$ & $0.47 \pm 0.05^{\mathrm{b}}$ & $0.80 \pm 0.09^{\mathrm{b}}$ & & $50.538 * *$ \\
\hline \multirow[t]{3}{*}{ H. c. } & $\mathrm{P} \%$ & - & 0 & 0.4 & 1.3 & $n s$ & \\
\hline & $\mathrm{MI} \pm \mathrm{SE}$ & - & 0 & 1.00 & 1.00 & & $n s$ \\
\hline & $\mathrm{MA} \pm \mathrm{SE}$ & - & 0 & $0.004 \pm 0.004$ & $0.01 \pm 0.01$ & & $n s$ \\
\hline \multirow[t]{3}{*}{$W . \mathrm{sp}}$. & P\% & - & 0 & 0 & 0.6 & $n s$ & \\
\hline & $\mathrm{MI} \pm \mathrm{SE}$ & - & 0 & 0 & 1.00 & & no test \\
\hline & $\mathrm{MA} \pm \mathrm{SE}$ & - & 0 & 0 & $0.006 \pm 0.004$ & & $n s$ \\
\hline \multirow[t]{3}{*}{ F. $a$. } & $\mathrm{P} \%$ & - & 0 & 0 & 0.3 & $n s$ & \\
\hline & $\mathrm{MI} \pm \mathrm{SE}$ & - & 0 & 0 & 1.00 & & no test \\
\hline & $\mathrm{MA} \pm \mathrm{SE}$ & - & 0 & 0 & $0.003 \pm 0.003$ & & $n s$ \\
\hline \multirow[t]{3}{*}{ Cest. } & $\mathrm{P} \%$ & - & $7.5^{\mathrm{a}}$ & $37.0^{\mathrm{b}}$ & $41.1^{\mathrm{b}}$ & $54.669 * *$ & \\
\hline & $\mathrm{MI} \pm \mathrm{SE}$ & - & $1.55 \pm 0.25^{\mathrm{ab}}$ & $1.28 \pm 0.07^{\mathrm{a}}$ & $2.00 \pm 0.16^{\mathrm{b}}$ & & $12.722^{*}$ \\
\hline & $\mathrm{MA} \pm \mathrm{SE}$ & - & $0.12 \pm 0.04^{\mathrm{a}}$ & $0.47 \pm 0.05^{\mathrm{b}}$ & $0.82 \pm 0.09^{\mathrm{b}}$ & & $54.422 * *$ \\
\hline \multirow[t]{3}{*}{ Nem. } & P\% & - & 0.7 & 1.3 & 2.2 & $n s$ & \\
\hline & $\mathrm{MI} \pm \mathrm{SE}$ & - & 1.00 & 1.00 & 1.00 & & $n s$ \\
\hline & $\mathrm{MA} \pm \mathrm{SE}$ & - & $0.01 \pm 0.01$ & $0.01 \pm 0.01$ & $0.02 \pm 0.01$ & & $n s$ \\
\hline Antelope Island & & $\mathrm{n}=199$ & $\mathrm{n}=79$ & $\mathrm{n}=267$ & - & & \\
\hline \multirow[t]{3}{*}{ C. $p$. } & $\mathrm{P} \%$ & $34.7^{\mathrm{a}}$ & $22.8^{\mathrm{a}}$ & $50.2^{\mathrm{b}}$ & - & $23.480 * *$ & \\
\hline & $\mathrm{MI} \pm \mathrm{SE}$ & $1.62 \pm 0.16$ & $1.11 \pm 0.08$ & $1.47 \pm 0.07$ & - & & $n s$ \\
\hline & $\mathrm{MA} \pm \mathrm{SE}$ & $0.56 \pm 0.08^{\mathrm{a}}$ & $0.25 \pm 0.06^{\mathrm{a}}$ & $0.74 \pm 0.06^{\mathrm{b}}$ & - & & $25.379 * *$ \\
\hline \multirow[t]{3}{*}{ H. c. } & $\mathrm{P} \%$ & 0.5 & 2.5 & 0 & - & $n s$ & \\
\hline & $\mathrm{MI} \pm \mathrm{SE}$ & 1.00 & 1.00 & 0 & - & & $n s$ \\
\hline & $\mathrm{MA} \pm \mathrm{SE}$ & $0.01 \pm 0.01^{\mathrm{ab}}$ & $0.03 \pm 0.02^{\mathrm{a}}$ & $0^{\mathrm{b}}$ & - & & $7.137 *$ \\
\hline \multirow[t]{3}{*}{ Cest. } & $\mathrm{P} \%$ & $35.2^{\mathrm{a}}$ & $25.3^{\mathrm{a}}$ & $50.2^{\mathrm{b}}$ & - & $20.123^{* *}$ & \\
\hline & $\mathrm{MI} \pm \mathrm{SE}$ & $1.61 \pm 0.15$ & $1.10 \pm 0.07$ & $1.47 \pm 0.07$ & - & & $n s$ \\
\hline & $\mathrm{MA} \pm \mathrm{SE}$ & $0.57 \pm 0.08^{\mathrm{a}}$ & $0.28 \pm 0.06^{\mathrm{a}}$ & $0.74 \pm 0.06^{\mathrm{b}}$ & - & & $22.395 * *$ \\
\hline \multirow[t]{3}{*}{ Nem. } & $\mathrm{P} \%$ & 0 & 2.5 & 2.6 & - & $n s$ & \\
\hline & $\mathrm{MI} \pm \mathrm{SE}$ & 0 & 1.00 & 1.00 & - & & $n s$ \\
\hline & $\mathrm{MA} \pm \mathrm{SE}$ & 0 & $0.03 \pm 0.02$ & $0.03 \pm 0.01$ & - & & $n s$ \\
\hline Antelope Island Causeway & & - & $\mathrm{n}=355$ & $\mathrm{n}=132$ & $\mathrm{n}=226$ & & \\
\hline \multirow[t]{3}{*}{ C. $p$. } & $\mathrm{P} \%$ & - & $33.5^{\mathrm{a}}$ & $9.8^{\mathrm{b}}$ & $65.9^{\mathrm{c}}$ & $120.024 * *$ & \\
\hline & $\mathrm{MI} \pm \mathrm{SE}$ & - & $1.29 \pm 0.05^{\mathrm{a}}$ & $1.31 \pm 0.13^{\mathrm{a}}$ & $2.56 \pm 0.15^{\mathrm{b}}$ & & $49.343 * *$ \\
\hline & $\mathrm{MA} \pm \mathrm{SE}$ & - & $0.43 \pm 0.04^{\mathrm{a}}$ & $0.13 \pm 0.04^{b}$ & $1.69 \pm 0.13^{\mathrm{c}}$ & & $148.381 * *$ \\
\hline \multirow[t]{3}{*}{ H. c. } & P \% & - & $27.6^{\mathrm{a}}$ & $29.5^{\mathrm{a}}$ & $0^{\mathrm{b}}$ & $78.932 * *$ & \\
\hline & $\mathrm{MI} \pm \mathrm{SE}$ & - & $1.02 \pm 0.01^{\mathrm{a}}$ & $1.13 \pm 0.05^{\mathrm{b}}$ & 0 & & $6.637 *$ \\
\hline & $\mathrm{MA} \pm \mathrm{SE}$ & - & $0.28 \pm 0.02^{\mathrm{a}}$ & $0.33 \pm 0.05^{\mathrm{a}}$ & $0^{\mathrm{b}}$ & & $78.813^{* *}$ \\
\hline \multirow[t]{3}{*}{ Cest. } & $\mathrm{P} \%$ & - & $49.3^{\mathrm{a}}$ & $31.8^{\mathrm{b}}$ & $65.9^{\mathrm{c}}$ & $39.985 * *$ & \\
\hline & $\mathrm{MI} \pm \mathrm{SE}$ & - & $1.45 \pm 0.05^{\mathrm{a}}$ & $1.45 \pm 0.11^{\mathrm{a}}$ & $2.56 \pm 0.15^{\mathrm{b}}$ & & $40.899 * *$ \\
\hline & $\mathrm{MA} \pm \mathrm{SE}$ & - & $0.72 \pm 0.05^{\mathrm{a}}$ & $0.46 \pm 0.07^{\mathrm{b}}$ & $1.69 \pm 0.13^{\mathrm{c}}$ & & $63.324 * *$ \\
\hline \multirow[t]{3}{*}{ Nem. } & P\% & - & $7.0^{\mathrm{a}}$ & $26.5^{\mathrm{b}}$ & $0^{\mathrm{c}}$ & $77.745 * *$ & \\
\hline & $\mathrm{MI} \pm \mathrm{SE}$ & - & $1.04 \pm 0.04$ & $1.06 \pm 0.04$ & 0 & & $n s$ \\
\hline & $\mathrm{MA} \pm \mathrm{SE}$ & - & $0.07 \pm 0.01^{\mathrm{a}}$ & $0.28 \pm 0.04^{b}$ & $0^{c}$ & & 77.713 ** \\
\hline Ogden Bay & & $\mathrm{n}=159$ & $\mathrm{n}=134$ & $\mathrm{n}=243$ & - & & \\
\hline \multirow[t]{3}{*}{ C.p. } & P\% & $28.3^{\mathrm{a}}$ & $15.7^{\mathrm{b}}$ & $33.3^{\mathrm{a}}$ & - & $13.623^{*}$ & \\
\hline & $\mathrm{MI} \pm \mathrm{SE}$ & $1.44 \pm 0.10$ & $1.43 \pm 0.15$ & $1.43 \pm 0.08$ & - & & $n s$ \\
\hline & $\mathrm{MA} \pm \mathrm{SE}$ & $0.41 \pm 0.06^{\mathrm{a}}$ & $0.22 \pm 0.05^{\mathrm{b}}$ & $0.48 \pm 0.05^{\mathrm{a}}$ & - & & $13.145^{*}$ \\
\hline \multirow[t]{3}{*}{ H. $c}$. & P\% & $0^{\mathrm{a}}$ & $0^{\mathrm{a}}$ & $6.6^{\mathrm{b}}$ & - & $20.104 * *$ & \\
\hline & $\mathrm{MI} \pm \mathrm{SE}$ & 0 & 0 & 1.00 & - & & no test \\
\hline & $\mathrm{MA} \pm \mathrm{SE}$ & $0^{\mathrm{a}}$ & $0^{\mathrm{a}}$ & $0.07 \pm 0.02^{b}$ & - & & $19.849 * *$ \\
\hline Cest. & $\mathrm{P} \%$ & $28.3^{\mathrm{a}}$ & $15.7^{\mathrm{b}}$ & $38.3^{\mathrm{a}}$ & - & $21.345^{* *}$ & \\
\hline & $\mathrm{MI} \pm \mathrm{SE}$ & $1.44 \pm 0.10$ & $1.43 \pm 0.15$ & $1.42 \pm 0.08$ & - & & $n s$ \\
\hline & $\mathrm{MA} \pm \mathrm{SE}$ & $0.41 \pm 0.06^{\mathrm{a}}$ & $0.22 \pm 0.05^{\mathrm{b}}$ & $0.54 \pm 0.05^{\mathrm{a}}$ & - & & $20.267^{* *}$ \\
\hline Nem. & $\mathrm{P} \%$ & 0.6 & 2.2 & 4.1 & - & $n s$ & \\
\hline & $\mathrm{MI} \pm \mathrm{SE}$ & 1.00 & 1.00 & 1.00 & - & & $n s$ \\
\hline & $\mathrm{MA} \pm \mathrm{SE}$ & $0.01 \pm 0.01$ & $0.02 \pm 0.01$ & $0.04 \pm 0.01$ & - & & $n s$ \\
\hline
\end{tabular}

Significant differences are presented, ${ }^{*} \mathrm{p}<0.05,{ }^{* *} \mathrm{p}<0.001 ; n s-$ not-significant; no test - test was not possible because the species was recorded in one month only. Different superscript letters denote statistically significant differences after Bonferroni correction. $\mathrm{n}$ - number of studied specimens; C. p. - Confluaria podicipina; H. c. - Hymenolepis (s. l.) californicus; W. sp. - Wardium sp.; F. a. - Fuhrmannolepis averini; Cest. - overall cestode infection; Nem. - Acuariidae gen. sp.; $\mathrm{P} \%$ - prevalence; $\mathrm{MI} \pm \mathrm{SE}$ - mean intensity; $\mathrm{MA} \pm \mathrm{SE}$ - mean abundance. 
increase in $\mathrm{P} \%$ and MA of $C$. podicipina and the overall cestode infection during entire sampling period. The lowest MA of overall cestode infection at this site was detected in July (Table 4) compared to August (Mann-Whitney test $U=12004, p=0.000$ ) and September (Mann-Whitney test $U=15357.5, p=0.000)$.

The infection of the second most abundant tapeworm species, H. (s. l.) californicus, did not demonstrate apparent seasonal trends. No significant differences were detected for this species between months at SM and AI. At the remaining two localities, there were significant temporal differences in $\mathrm{P} \%$ and MA (Table 4). At AIC, the highest $\mathrm{P} \%$ of this parasite was registered in August; in September, we did not find any brine shrimp infected by this species; MI of this parasite was significantly higher in August than in July (Mann-Whitney test $U=1705, p=0.010$ ). At OB, cysticercoids of $H$. (s. l.) californicus were found in August only.

Concerning the dynamics of nematodes, we detected significant differences in $\mathrm{P} \%$ and $\mathrm{MA}$ at $\mathrm{AIC}$, being the highest in August (Table 4).

\section{DISCUSSION}

\section{Species composition of helminth larvae}

Our results demonstrate that Artemia franciscana participates in the life cycles of at least five helminth species at GSL. These include cestodes parasitic in grebes, phalaropes and gulls, an unidentified cestode which might be a parasite of charadriiform hosts and an unidentified acuariid nematode species.

Previous studies in Europe have revealed that the prevalence of avian cestodes in brine shrimps may depend on the seasonal presence of definitive hosts at certain hypersaline wetlands (Georgiev et al. 2005, 2014, Sánchez et al. 2013). GSL is the most significant saline ecosystem in North America and has been classified as a Western Hemispheric Shorebird Reserve due to its great importance for migratory shorebirds (Andres et al. 2006, Caudell and Conover 2006). Around 5 million birds, representing ca 250 species, use GSL annually. The second largest staging population of the eared grebe (Podiceps nigricollis) in North America (1.4 million) is recorded in the lake and its diet largely consists of brine shrimps (Paul and Manning 2002, Caudell and Conover 2006). In addition, California gull, Wilson's phalarope (Phalaropus tricolor), red-necked phalarope, American avocet [Recurvirostra americana (Gmelin)], black-necked Stilts [Himantopus mexicanus (Müller)], marbled godwit [Limosa fedoa (Linnaeus)] and snowy plover (Charadrius alexandrinus Linnaeus) are abundant in this lake (Paul and Manning 2002).

A survey of avian communities of GSL was carried out during the period April 2008-September 2011. The bird community at our sampling sites and adjacent areas consisted of 33 species, many of them in substantial numbers (Table S1). The most abundant birds such as eared grebes, shorebirds and gulls, were numerous throughout the year at all surveyed sites. These data correspond to the species composition of helminth parasites in A. franciscana.
Whereas C. podicipina and H. (s. l.) californicus were abundant, the remaining two cestode species, probably parasitic in charadriiform birds, had low infection rates. The low prevalence of parasites of charadriiform birds might be explained by the fact that three of the sampling areas (OB, SM and AI) were rather deep-water sites unsuitable for waders. With the great variety and abundance of shorebirds inhabiting GSL, it can be expected that $A$. franciscana plays a role as intermediate host for further cestode species, especially these parasitic in waders (Charadriiformes) in shallow waters.

\section{Spatial and temporal variations in parasite infections and bird abundance}

In GSL, brine shrimps generally hatch from overwintering cysts in March-April and largely disappear in December at water temperature $<4^{\circ} \mathrm{C}$ (Belovsky et al. 2011). The present study revealed variations in $\mathrm{P} \%$ and $\mathrm{MA}$ of three species, which strongly influenced temporal and spatial variations of the overall parasite infection in A. franciscana from GSL. These species were C. podicipina, H. (s. l.) californicus and larvae of acuariid nematodes. The adjacent sites AI and AIC are characterised with highest parameters of overall parasite infection (Table 3). The most diverse and abundant bird community (33 species in high counts) during the period April-September has been registered at this region (Table S1). The northern part of AI and the associated causeway offer habitats varying from rocky shorelines and dikes to open waters. They are suitable places for grebes using open waters as well as gulls and shorebirds using shorelines.

Confluaria podicipina was the most prevalent and abundant cestode species in all the sites examined that corresponds to the bird host numbers (Table S1). Eared grebes utilise GSL primarily as a fall staging area but thousands of them also use open waters of the lake in summer. The ornithological survey showed consistently high counts of grebes at AI and AIC throughout the sampling period. For $\mathrm{OB}$, the survey presented low counts of grebes, which might be due to the methodology (observations from airboats). However, a previous waterbird survey in 1997-2001 (Paul and Manning 2002) reported airplane observations of OB detecting higher counts (mean 85164 grebes, with a peak of 149604 birds).

Previous studies in Spain demonstrated that infection levels with the grebe specialist $C$. podicipina in the diploid population of $A$. parthenogenetica at Odiel Marshes positively correlate with the number of their definitive hosts (Sánchez et al. 2013). The high abundance of the eared grebes at GSL suggests that our results on the substantial infection rates of $C$. podicipina were to be expected.

Confluaria podicipina showed a distinct seasonal pattern, with the prevalence and abundance varying significantly among months at all sites. However, monthly counts of $P$. nigricollis at individual sampling sites were not in agreement with the seasonal changes of $C$. podicipina in brine shrimps. Seasonal variations seem to be partly determined by the abundance of the final host, the eared grebes, which arrive in large number in GSL in autumn and early 
winter to moult. This could explain the gradual increase of the parameters of infection with $C$. podicipina during the sampling period (June-September) as a general pattern observed at SM, an open water area with shallow shorelines and beaches. However, the remaining sampling sites are characterised with a different model of temporal variations, where the lowest infection rates with $C$. podicipina were at the middle of the sampling period (Table 4). The survey of aquatic birds showed that OB, Farmington Bay and the region around the east coast of $\mathrm{AI}$ and its causeway are the locations with the highest density of the grebe population (Paul and Manning 2002). The mean annual counts of the eared grebes at OB were $19-90 \%$ of the total population of this bird at the lake. During periods of high bird density, it is possible that grebes could selectively remove infected shrimps, as demonstrated for sandpipers (Sánchez et al. 2009b). The high bird density could affect the transmission of the parasite leading to a reduction in its prevalence and abundance in a certain period (Sánchez et al. 2013). Currently, our result cannot reveal the exact mechanism explaining the observed temporal dynamics of the cestode infection, as much longer period of sampling and more accurate monthly census of aquatic birds are needed.

In the case of $H$. (s. l.) californicus, the present study demonstrates spatial variations with significantly higher prevalence and abundance at AIC and OB. In general, these results correspond with data from the bird survey showing the highest counts of the final hosts Larus californicus and L. delawarensis at these sites during summer and fall (Table S1). In August and September, California gulls are found exploiting large numbers of brine flies and brine shrimps in open water and shoreline areas (Greenhalgh 1952, Paul and Manning 2002). In the same time, our results record significant temporal variations of prevalence and abundance of $H$. (s. l.) californicus at AIC, with the highest values in July-August. Despite the slight increase in counts of gulls from June to September, we cannot confirm that monthly counts of gulls are in agreement with the dynamics of infection. Moreover, the single day counts of L. californicus and L. delawarensis in September are very high (more than 3000 birds) and no single brine shrimp infected with $H$. (s. l.) californicus has been found at this site in September. At OB, cysticercoids of $H$. (s. l.) californicus were found in brine shrimps only in August, despite the high number of gulls at this site in July.

As for the nematode infections, the present study shows that $A$. franciscana can act as intermediate hosts of acuariid nematodes in its native range and provides information of the infection dynamics. The spatial variations in the prevalence and abundance of nematodes were significant, with highest values at AIC (Table 3) and highest prevalence and abundance in August at AIC (Table 4). However, we cannot link the results with the dynamics of a certain avian species or group.

\section{Helminth infections in native vs introduced populations of $\boldsymbol{A}$. franciscana}

Until now, 18 cestode species have been reported to use species of Artemia as intermediate host (Table S3). The comparison of the cestode infections among the native GSL population of $A$. franciscana, its introduced populations in the Mediterranean and the native populations of A. parthenogenetica (diploid form) and A. salina in the Palaearctic Region reveals substantial differences in the species composition of cestodes. Until now, A. parthenogenetica (diploid populations) and A. salina are known to serve as intermediate hosts for 12 and 15 cestode species, respectively. In contrast, only four species occur in the native population of $A$. franciscana in Utah, with two of them reported also in the Palaearctic Region (C. podicipina and F. averini). These differences can be explained by the presence and abundance of birds predating on brine shrimps at a certain locality. Seven out of 18 cestode species recorded in Artemia spp. (39\%) are specific parasites of flamingos, an avian group which does not occur at GSL. At the same time, C. podicipina is the most prevalent species in A. franciscana in Utah. The present study reveals an interesting phenomenon. Despite the Holarctic distribution of $C$. podicipina (Vasileva et al. 2000), this cestode has not been found in introduced populations of $A$. franciscana in Europe. However, $C$. podicipina has been recorded in the two native European species of Artemia and the present study demonstrates that $A$. franciscana is a susceptible intermediate host of this species. The habitats in Spain, France or Portugal where previous studies on introduced populations of $A$. franciscana have been carried out (Georgiev et al. 2007, 2014, Vasileva et al. 2009, Sánchez et al. 2012b) are shallow salt ponds, where no grebes or a few grebe individuals have been recorded.

$H$. (s. l.) californicus is a parasite of Nearctic gulls and, therefore, does not occur in A. franciscana from its invasive range in the Palaearctic Region. However, in its invasive habitats, A. franciscana participates (although with low infection rates) in the circulation of at least nine cestodes parasitic in other groups of aquatic birds that do not occur in its native geographical range, e.g. flamingos and shelducks (Table S3), despite the lack of long-term co-evolutionary processes between the American brine shrimps and the Palaearctic cestode parasites. Having in mind the high abundance of charadriiform birds at GSL and the numerous records of cestodes using them as definitive hosts (Table S2), it can be expected that further cestode species occur in A. franciscana in its native habitats in America.

The overall cestode infection in the native population of A. franciscana in GSL is much higher than in the introduced populations of the same host in the Palaearctic Region (Table 5). The prevalence and abundance of C. podicipina in A. franciscana is particularly high. The comparison of these results with the infection rates in the same host in its invasive habitats in Europe (Georgiev et al. 2007, 2014, Sánchez et al. 2012b) is in agreement with the hypothesis that $A$. franciscana has a lower susceptibility to the Palaearctic cestode parasites than to cestode parasites in its native range. From another point of view, the values of the infection descriptors in the native $A$. franciscana in GSL are comparable to those of native populations of the Palaearctic brine shrimps (Table 5). It seems that the differences in the parasite susceptibility of Artemia spp. and the 
Table 5. Comparison of infective descriptors with cysticercoids between populations of brine shrimps Artemia parthenogenetica (A. p.), A. salina (A.s.) and native and invasive populations of A. franciscana (A.f.).

\begin{tabular}{|c|c|c|c|c|c|c|c|c|}
\hline \multirow{2}{*}{$\begin{array}{l}\text { Brine } \\
\text { shrimp } \\
\text { species }\end{array}$} & \multirow{2}{*}{ Locality (country) } & \multicolumn{3}{|c|}{ Total (cysticercoids) } & \multicolumn{3}{|c|}{ Confluaria podicipina } & \multirow{2}{*}{ References } \\
\hline & & $\mathrm{P} \%$ & $\mathrm{MI} \pm \mathrm{SE}$ & $\mathrm{MA} \pm \mathrm{SE}$ & $\mathrm{P} \%$ & $\mathrm{MI} \pm \mathrm{SE}$ & $\mathrm{MA} \pm \mathrm{SE}$ & \\
\hline A. $p$. & Odiel (Spain) & 26.8 & $1.71 \pm 1.28$ & $0.44 \pm 0.99$ & 6.5 & $1.42 \pm 0.82$ & $0.09 \pm 0.40$ & Georgiev et al. (2005) \\
\hline A. $p$. & Odiel (Spain) & 47.0 & $3.62 \pm 0.38$ & $1.70 \pm 0.22$ & 2.0 & $1.25 \pm 0.25$ & $0.02 \pm 0.01$ & Georgiev et al. (2007) \\
\hline A. $p$. & SNSR, Sanlúcar, (Spain) & 69.0 & $2.04 \pm 0.10$ & $1.40 \pm 0.10$ & - & - & - & Georgiev et al. (2007) \\
\hline A. $p$ & SP, Sanlúcar, (Spain) & 89.0 & $1.97 \pm 0.08$ & $1.80 \pm 0.08$ & - & - & - & Georgiev et al. (2007) \\
\hline A. $p$. & Summer, Aigues Mortes (France) & 70.9 & $1.97 \pm 0.08$ & $1.40 \pm 0.08$ & - & - & - & Sánchez et al. (2012a) \\
\hline A. $p$. & Winter, Aigues Mortes (France) & 66.7 & $2.33 \pm 0.72$ & $1.46 \pm 0.60$ & - & - & - & Sánchez et al. (2012a) \\
\hline A. $s$. & Almeria (Spain) & 83.0 & $2.99 \pm 0.14$ & $2.48 \pm 0.14$ & 6.0 & $1.15 \pm 0.10$ & $0.07 \pm 0.02$ & Georgiev et al. (2007) \\
\hline A.f. & Castro Marim (Portugal) & 9.0 & $1.09 \pm 0.09$ & $0.10 \pm 0.02$ & - & - & - & Georgiev et al. (2007) \\
\hline A. $f$. & SLA, Puerto Real (Spain) & 24.3 & $1.12 \pm 0.08$ & $0.27 \pm 0.10$ & - & - & - & Georgiev et al. (2007) \\
\hline A. $f$. & SSB, Puerto Real (Spain) & 2.0 & $1.40 \pm 0.40$ & $0.03 \pm 0.02$ & - & - & - & Georgiev et al. (2007) \\
\hline A. $f$. & Summer, Aigues Mortes (France) & 1.5 & $1.00 \pm 0.00$ & $0.02 \pm 0.01$ & - & - & - & Sánchez et al. (2012a) \\
\hline A.f. & Winter, Aigues Mortes (France) & 0.7 & 1.11 & $0.01 \pm 0.005$ & - & - & - & Sánchez et al. (2012a) \\
\hline A.f. & La Tapa (Spain) & 5.9 & $1.16 \pm 0.07$ & $0.07 \pm 0.01$ & - & - & - & Georgiev et al. (2014) \\
\hline A.f. & GSL, Utah (USA) & 39.2 & $1.68 \pm 0.04$ & $0.66 \pm 0.02$ & 34.9 & $1.69 \pm 0.04$ & $0.59 \pm 0.02$ & Present study \\
\hline
\end{tabular}

GSL - Great Salt Lake; SNSR - Salinas Nuestra Señora del Rocío; SP - Salinas Portuguesas; SLA - Salinas Las Ánimas; SSB -Salinas Santa Bárbara; $\mathrm{P} \%$ - prevalence; $\mathrm{MI} \pm \mathrm{SE}$ - mean intensity; $\mathrm{MA} \pm \mathrm{SE}$ - mean abundance.

different infection rates between the native and introduced populations of $A$. franciscana depend on the evolutionary time needed for co-adaptation and establishment of hostparasite associations. If this assumption is correct, then the infections will increase over time as native cestodes become adapted to their newly-acquired invasive hosts (Georgiev et al. 2007).

In conclusion, the results of this first study on the parasite infection of native populations of American brine shrimps revealed that $A$. franciscana participates in the life cycles of helminths of aquatic birds in its native habitats. The species composition of helminth parasites and the spatial variations in their prevalence and abundance may reflect the abundance and distribution of aquatic birds serving as definitive hosts.

The population of $A$. franciscana from GSL is characterised by high prevalence, intensity and abundance of the overall cestode infection in contrast to the introduced populations of this species in the Palaearctic Region. At the same time, the values of the infective descriptors in native populations of $A$. franciscana are slightly lower or in some cases similar to those in the Palaearctic species $A$. parthenogenetica (diploid populations) and $A$. salina in their native habitats. Additional studies are needed to estimate if parasites can modify the appearance and behaviour of the native populations of American brine shrimp in the same way and with such significant fitness costs as they do with the Palaearctic Artemia spp. (Amat et al. 1991, Sánchez et al. 2009a).

Acknowledgements. We are grateful to the staff of the Zoology Department at Weber State University, Utah, for their help in field work and obtaining the bird counts data. Particular thanks are due to John Neil and the Utah Division of Wildlife Resources for providing us with the bird survey data. Many thanks to Mrs P. Pilitt, U.S. National Parasite Collection, for loaning paratypes of $H y$ menolepis californicus. The study has been supported by Spanish National Plan R\&D (project CGL-2005-02306/BOS), EC-funded project WETLANET (FP7, Capacities, Grant 229802) and the Project CEBDER (Grant DO-02-15) funded by the National Science Fund of the Republic of Bulgaria. S. Redón was supported by a PhD fellowship (FPI) from the Ministry of Science and Innovation of Spain.

\section{REFERENCES}

Abatzopoulos T.J., Beardmore J.A., Clegg J.S., Sorgeloos P. (Eds.) 2002: Artemia: Basic and Applied Biology. Kluwer Academic Publishers, Dordrecht, 304 pp.

Amat F., Barata C., Hontoria F., Navarro J.C., Varó I. 1995 Biogeography of the genus Artemia (Crustacea, Branchiopoda, Anostraca) in Spain. Int. J. Salt Lake Res. 3: 175-190.

Amat F., Gozalbo A., Navarro J.C., Hontoria F., Varó I. 1991: Some aspects of Artemia biology affected by cestode parasitism. Hydrobiologia 212: 39-44.

Amat F., Hontoria F., Navarro J.C., Vieira N., Mura G. 2007: Biodiversity loss in the genus Artemia in the Western Mediterranean region. Limnetica 26: 387-404.

Amat F., Hontoria F., Ruiz O., Green A.J., Sánchez M.I., Figuerola J., Hortas F. 2005: The American brine shrimp as an exotic invasive species in the western Mediterranean. Biol. Inv. 7: $37-47$.
Anderson R.C. 2000: Nematode Parasites of Vertebrates. Their Development and Transmission. Second Edition. CAB International, Wallingford, $649 \mathrm{pp}$.

Anderson R.C., Wong P.L. 1992: Western Palaearctic and Ethiopian species of Skrjabinoclava (Nematoda: Acuarioidea) in Icelandic shorebirds (Aves: Charadriiformes) en route to breed in the New World and Greenland. Can. J. Zool. 70: 1861-1877.

Andres B., Clay R., Duncan C. 2006: Shorebird species of conservation concern in the western hemisphere. Western Hemisphere Shorebird Reserve Network, http://www.whsrn.org/ about-shorebirds/shorebird-status.

Bartlett C.M., Anderson R.C., Wong P.L. 1989: Development of Skrjabinocerca prima (Nematoda: Acuarioidea) in $\mathrm{Hy}$ alella azteca (Amphipoda) and Recurvirostra americana (Aves: Charadriiformes), with comments on its precocity. Can. J. Zool. 67: $2883-2892$. 
Baruš V., Sergeeva T.P., Sonin M.D., Ryzhikov K.M. 1978: Helminths of Fish-eating Birds of the Palaearctic Region. I. Nematoda. Academia, Moscow and Prague, 318 pp.

Belovsky G.E., Stephens D., Perschon C., Birdsey P., Paul D., Naftz D., Baskin R., Larson C., Mellison C., Luft J., Mosley R., Mahon H., Van Leeuwen J., Allen D.V. 2011: The Great Salt Lake Ecosystem (Utah, USA): long term data and a structural equation approach. Ecosphere 2: 33.

Ben Naceur H., Ben Rejeb Jenhani A., Romdhane M.S. 2010 Biological characterization of the new invasive brine shrimp $\mathrm{Ar}$ temia franciscana in Tunisia: Sabkhet Halk El-Menzel. Int. J. Biol. Life Sci. 6: 131-137.

Bondarenko S., Kontrimavichus V. 2004a: On Branchiopodataenia n. g., parasitic in gulls, and its type-species, $B$. anaticapicirra n. sp. (Cestoda: Hymenolepididae). Syst. Parasitol. 57: 119-133.

Bondarenko S., Kontrimavichus V. 2004b: Life-cycles of cestodes of the genus Branchiopodataenia Bondarenko \& Kontrimavichus, 2004 (Cestoda: Hymenolepididae) from gulls in Chukotka. Syst. Parasitol. 57: 191-199.

BondARENKo S.K. 1997: [Life-cycle of Wardium fryei (Cestoda: Hymenolepididae).] Parazitologiya 31: 142-156 (In Russian.)

Bondarenko S.K., Kontrimavichus V.L. 2006: [Aploparaksidae of Wild and Domesticated birds, Volume 14. Fundamentals of Cestodology.] Nauka, Moscow, 433 pp. (In Russian.)

Bondarenko S.K., Petkevichiute R. 1998: [On the type species of the genus Wardium - W. fryei (Cestoda: Hymenolepididae: Aploparaksinae)]. Parazitologiya 32: 221-235. (In Russian.)

Bush A.O., Lafferty K.D., Lotz J.M., Shostak A.W. 1997: Parasitology meets ecology on its own terms: Margolis et al. revisited. J. Parasitol. 83: 575-583.

Caudell J.N., Conover M.R. 2006: Behavioural and physiological responses of eared grebes (Podiceps nigricollis) to variations in brine shrimp (Artemia franciscana) densities. West. N. Am. Naturalist 66: 12-22.

Chabaud A.G. 1950: Cycle évolutif de Synhimantus (Desportesius) spinulatus (Nematoda, Acuariidae). Ann. Parasitol. Hum. Comp. 25: 150-166.

Chabaud A.G. 1975: Keys to the genera of the order Spirurida Part 2. Spiruroidea, Habronematoidea and Acuarioidea. In: R.C. Anderson, A.G. Chabaud and S. Willmott (Eds.), CIH Keys to the Nematode Parasites of Vertebrates, No. 3. Commonwealth Agricultural Bureaux, Farnham Royal, Bucks: pp. 1-58.

Chervy L. 2002: The terminology of larval cestodes or metacestodes. Syst. Parasitol. 52: 1-33.

Deblock S., Rausch R.L. 1967: Les Hymenolepis (s.l.) de Charadriiformes (4e note à propos de deux espèces nouvelles d'Alaska). Ann. Parasitol. Hum. Comp. 42: 303-311.

DunN A.M. 2009: Parasites and biological invasions. Adv. Parasitol. 68: $161-184$.

Dunn A.M., Torchin M.E., Hatcher M.J., Kotanen P.M., Blumenthal D.M., Byers J.E., Coon C.A.C., Frankel V.M., Holt R.D., Hufbauer R.A., Kanarek A.R., Schierenbeck K.A., Wolfe L.M., Perkins S.E. 2012: Indirect effects of parasites in invasions. Funct. Ecol. 26: 1262-1274.

Georgiev B.B., Angelov A., Vasileva G.P., Sanchez M.I., Hortas F., Mutafchiev Y., Pankov P., Green A.J. 2014: Larval helminths in the invasive American brine shrimp $A r$ temia franciscana throughout its annual cycle. Acta Parasitol. 59: $380-389$.

Georgiev B.B., Sánchez M.I., Green A.J., Nikolov P.N., Vasileva G.V., Mavrodieva R.S. 2005: Cestodes from $\mathrm{Ar}$ temia parthenogenetica (Crustacea, Branchiopoda) in the Odiel marshes, Spain: a systematic survey of cysticercoids. Acta Parasitol. 50: 105-117.

Georgiev B.B., Sánchez M.I., Vasileva G.P., Nikolov P.N., Green A.J. 2007: Cestode parasitism in invasive and native brine shrimps (Artemia sp.) as a possible factor promoting the rapid invasion of $A$. franciscana in the Mediterranean region. Parasitol. Res. 101: 1647-1655.
Great Salt Lake Ecosystem Program 2010: World Wide Web electronic publication, www.wildlife.utah.gov/gsl/, 5/2015

Green A.J., Sánchez M.I., Amat F., Figuerola J., Hontoria F., Ruiz O., Hortas F. 2005: Dispersal of invasive and native brine shrimps Artemia (Anostraca) via waterbirds. Limnol. Oceanogr. 50: 737-742.

Greenhalgh C.M. 1952: Food habits of the California Gull in Utah. Condor 54: 302-308.

Hontoria F., Navarro J.C., Varó I., Gozalbo A., Amat F., Vieira N. 1987: Ensayo de caracterización de cepas autóctonas de Artemia de Portugal. Séminario sobre aquacultura. Instituto Ciencias Biomédicas "Abel Salazar". Porto (Portugal). Publ. Inst. C. Biomed., 10 pp.

Hontoria F., Redón S., Maccari M., Varó I., Navarro J.C., Ballell L., Amat F. 2012: A revision of Artemia in Macaronesia. Aquatic Biosystems 8: 25.

JARECKA L. 1960: Life cycles of tapeworms from lakes Goldapivo and Mamry Polnoczne. Acta Parasitol. Pol. 8: 47-66.

Jehl J.R., Johansson C. 2002: Autumnal migration of eared grebes (Podiceps nigricollis) through southwestern Wyoming: a key to assessing the size of the North American population. West. N. Am. Naturalist 62: 335-340.

KrabBe H. 1869: [Contribution to the Knowledge of Tapeworms of Birds.] Biologiske Skrifter, Kjøbenhavn: Ræk. 5, Afd. 8, Bd. 5, 120 pp. (In Danish.)

MAKSIMOVA A.P. 1977: [Branchiopods as intermediate hosts of the cestode Anomolepis averini (Spassky et Yurpalova, 1967) (Cestoda: Dilepididae).] Parazitologiya 11: 77-79. (In Russian.)

Maksimova A.P. 1981: [Morphology and life cycle of the cestode Confluaria podicipina (Cestoda: Hymenolepididae).] Parazitologiya 15: 325-331. (In Russian.)

MAKsimOVA A.P. 1986: [On the morphology and biology of the cestode Wardium stellorae (Cestoda: Hymenolepididae).] Parazitologiya 20: 487-491. (In Russian.)

Maksimova A.P. 1987: [On the morphology and the life cycle of the cestode Wardium fusa (Cestoda: Hymenolepididae).] Parazitologiya 21: 157-159. (In Russian.)

Manning A.E., Paul D.S. 2003: Migratory waterbird use of the Great Salt Lake ecosystem. Great Basin Birds 6: 5-17.

Miller R.G. 1981: Simultaneous Statistical Inference. Springer, Berlin, Heidelberg, New York, 299 pp.

Mura G., Kappas I., Baxevanis A.D., Moscatello S., D’Amico Q., López G.M., Hontoria F., Аmat F., AватzoPoulos T.J. 2006: Morphological and molecular data reveal the presence of the invasive Artemia franciscana in Margherita di Savoia salterns (Italy). Int. Rev. Hydrobiol. 91: 539-554.

Mutafchiev Y., Georgiev B.B. 2008: Redescription of Decorataria decorata (Spirurida, Acuariidae) based on nematodes from Podiceps cristatus and P. grisegena (Aves, Podicipediformes) from Bulgaria. Acta Parasitol. 53: 158-164.

Mutafchiev Y., Halajian A., Georgiev B.B. 2010: Two new nematode species of the genus Cosmocephalus Molin, 1858 (Spirurida: Acuariidae), with an amended generic diagnosis and an identification key to Cosmocephalus spp. Zootaxa 2349: 1-20.

Paul D.S., Manning A.E. 2002: Great Salt Lake Waterbird Survey Five-Year Report (1997-2001). Utah Division of Wildlife Resources, Salt Lake City, Publication No. 08-38, 56 pp.

Pinto P.M., Аmat F., Almeida V.D., Vieira N. 2013: Review of the biogeography of Artemia Leach, 1819 (Crustacea: Anostraca) in Portugal. Int. J. Artemia Biol. 3: 51-56.

Prenter J., MacNeil C., Jaimie T.A., Dunn A.M. 2004: Roles of parasites in animal invasions. Trends Ecol. Evol. 19: 385-390.

SÁnchez M.I., Georgiev B.B., Green A.J. 2007b: Avian cestodes affect the behaviour of their intermediate host Artemia parthenogenetica: an experimental study. Behav. Processes 74: 293-299.

SÁnchez M.I., Georgiev B.B., Nikolov P.N., Vasileva G.P., Green A.J. 2006: Red and transparent brine shrimps (Artemia parthenogenetica): a comparative study of their cestode infections. Parasitol. Res. 100: 111-114. 
Sánchez M.I., Green A.J., Amat F., Castellanos E.M. 2007a: Transport of brine shrimps via the digestive system of migratory waders: dispersal probabilities depend on diet and season. Mar. Biol. 151: 1407-1415.

Sánchez M.I., Hortas F., Figuerola J., Green A.J. 2009b: Sandpipers select red brine shrimps rich in both carotenoids and parasites. Ethology 115: 196.

Sánchez M. I., Hortas F., Figuerola J., Green A.J. 2012a: Comparing the potential for dispersal via waterbirds of a native and an invasive brine shrimp. Freshwater Biol. 57: 1896-1903.

Sánchez M.I., Nikolov P.N., Georgieva D.D., Georgiev B.B. Vasileva G.P., Pankov P., Paracuellos M., Lafferty K.D., Green A.J. 2013: High prevalence of cestodes in Artemia spp. throughout the annual cycle: relationship with abundance of avian final hosts. Parasitol. Res. 112: 1913-1923.

Sánchez M.I., Rode N.O., Flaven E., Redón S., Amat F., VASileva G.P., Lenormand T. 2012b: Differential susceptibility to parasites of invasive and native species of Artemia living in sympatry: consequences for the invasion of $A$. franciscana in the Mediterranean region. Biol. Invasions 14: 1819-1829.

Sánchez M.I., Thomas F., Perrot-Minnot M.J., Biron D.G., Bertrand-Michel J., Missé D. 2009a: Neurological and physiological disorders in Artemia harbouring manipulative cestodes. J. Parasitol. 95: 20-24.

Scalone R., Rabet N. 2013: Presence of Artemia franciscana (Branchiopoda, Anostraca) in France: morphological, genetic, and biometric evidences. Aquat. Invasions 8: 67-76.

Skryabin K.I., Sobolev A.A., Ivashkin V.M. 1965: [Spirurata of Animals and Man and the Diseases Caused by Them. Spirurata. Part 3. Acuarioidea.] In: Skryabin K.I. (Ed.) Osnovy Nematodologii 14. Nauka, Moscow, 572 pp. (In Russian.).

Smogorzhevskaya L.A. 1990: [Nematodes. Part 3. Acuarioidea.] In: Sharpilo V.P. (Ed.) Fauna Ukrainy 32. Naukova Dumka, Kiev, 188 pp. (In Russian).

Spasskaya L.P. 1966: [Cestodes of Birds of the USSR. Hymenolepididae.] Nauka, Moscow, 700 pp. (In Russian.)

Spasskaya L.P., Spassky A.A. 1978: [Cestodes of Birds in the USSR. Dilepididae of Aquatic Birds.] Nauka, Moscow, 316 pp. (In Russian.)

Spassky A.A., Yurpalova N.M. 1967: [Fuhrmanolepis averini, $\mathrm{n}$. sp. - new dilepidid species from waders in Chukotka.] Buletinul akademiey de Shtiince a RSS Moldovenyasht'. Seriya biologicheskikh i khimicheskikh nauk 1: 17-22. (In Russian.)

Spassky A.A., Yurpalova N.M., Kornyushin V.V. 1968: [A new genus of Dilepididae - Anomolepis gen. n. (Cestoda, Cyclophyllidea)]. Vestnik Zool. 5: 46-51. (In Russian.)

Stock T.M., Holmes J.C. 1987: Host specificity and exchange of intestinal helminths among four species of grebes (Podicipedidae). Can. J. Zool. 65: 669-676.

Thiéry A., Robert F. 1992: Bisexual populations of the brine shrimp Artemia in Sète-Villeroy and Villeneuve saltworks (Languedoc, France). Int. J. Salt Lake Res. 1: 47-63.
Tomilovskaya N.S. 1975: [Larvae of dilepidid cestodes from Chaun Lowland.] In: Parasites of North-Eastern Asia. Vladivostok, pp. 224-232. (In Russian.)

Torchin M.E., Lafferty K.D., Dobson A.P., McKenzie V.J., KURIS A.M. 2003: Introduced species and their missing parasites. Lett. Nature 421: 628-630.

Triantaphyllidis G.V., Abatzopoulos T.J., Sorgeloos P. 1998: Review of the biogeography of the genus Artemia (Crustacea, Anostraca). J. Biogeogr. 25: 213-226.

Varó N., Green A.J., Sánchez M.I., Ramo C., Gómez J., Amat J.A. 2011: Behavioural and population responses to changing availability of Artemia prey by moulting black-necked grebes, Podiceps nigricollis. Hydrobiologia 664: 163-171.

Vasileva G.P., Georgiev B.B., Genov T. 2000: Palaearctic species of the genus Confluaria Ablasov (Cestoda, Hymenolepididae): redescriptions of C. podicipina (Szymanski, 1905) and $C$. furcifera (Krabbe, 1869), description of C. pseudofurcifera $\mathrm{n}$. sp., a key and final comments. Syst. Parasitol. 45: 109-130.

Vasileva G.P., Redón S., Amat F., Nikolov P.N., Sánchez M.I., Lenormand T., Georgiev B.B. 2009: Records of cysticercoids of Fimbriarioides tadornae Maksimova, 1976 and Branchiopodataenia gvozdevi (Maksimova, 1988) (Cyclophyllidea, Hymenolepididae) from brine shrimps at the Mediterranean coasts of Spain and France, with a key to cestodes from Artemia spp. from the Western Mediterranean. Acta Parasitol. 54: $143-150$.

Wong P.L., Anderson R.C. 1982: The transmission and development of Cosmocephalus obvelatus (Nematoda: Acuarioidea) of gulls (Laridae). Can. J. Zool. 60: 1426-1440.

Wong P.L., Anderson R.C. 1986: Revision of the genus Desportesius Chabaud and Campana, 1949 (Nematoda: Acuarioidea) mainly from the gizzard of ciconiiform birds. Can. J. Zool. 64: $2520-2530$.

Wong P.L., Anderson R.C. 1987: Development of Syncuaria squamata (Linstow, 1883) (Nematoda: Acuarioidea) in ostracods (Ostracoda) and double-crested cormorants (Phalacrocorax auritus auritus). Can. J. Zool. 65: 2524-2531.

Wong P.L., Anderson R.C. 1993: New and described species of nematodes from shorebirds (Charadriiformes) collected in spring in Iceland. Syst. Parasitol. 25: 187-202.

Wong P.L., Anderson R.C., Bartlett C.M. 1989: Development of Skrjabinoclava inornata (Nematoda: Acuarioidea) in fiddler crabs (Uca spp.) (Crustacea) and western willets (Catoptrophorus semipalmatus inornatus) (Aves: Scolopacidae). Can. J. Zool. 67: 2893-2901.

Wurtsbaugh W.A., Gliwicz M. 2001: Limnological control of brine shrimp population dynamics and cyst production in the Great Salt Lake, Utah. Hydrobiologia 466: 119-132.

Young R.T. 1950: Cestodes of California gulls. J. Parasitol. 36: 9-12.

Young R.T. 1952: The larva of Hymenolepis californicus in the brine shrimp (Artemia salina). J. Wash. Acad. Sci. 42: 385-388. 